\title{
NRC Multiphysics Analysis Capability Deployment FY 2021 - Part 2
}

\section{April 2021}

Cole M. Mueller ${ }^{1}$, Ching-Sheng Lin ${ }^{2}$, and Javier Ortensi ${ }^{2}$

${ }^{1}$ Thermal Fluid Systems Methods and Analysis

${ }^{2}$ Reactor Physics Methods and Analysis

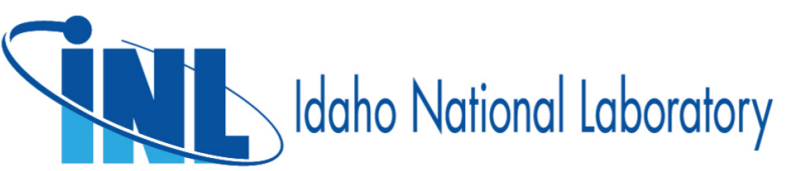

INL is a U.S. Department of Energy National Laboratory operated by Batelle Energy Alliance, LLC 


\section{DISCLAIMER}

This information was prepared as an account of work sponsored by an agency of the U.S. Government. Neither the U.S. Government nor any agency thereof, nor any of their employees, makes any warranty, expressed or implied, or assumes any legal liability or responsibility for the accuracy, completeness, or usefulness, of any information, apparatus, product, or process disclosed, or represents that its use would not infringe privately owned rights. References herein to any specific commercial product, process, or service by trade name, trade mark, manufacturer, or otherwise, does not necessarily constitute or imply its endorsement, recommendation, or favoring by the U.S. Government or any agency thereof. The views and opinions of authors expressed herein do not necessarily state or reflect those of the U.S. Nuclear Regulatory Commission. 
INL/EXT-21-62522

\title{
NRC Multiphysics Analysis Capability Deployment FY 2021 - Part 2
}

\author{
Cole M. Mueller ${ }^{1}$, Ching-Sheng Lin $^{2}$, and Javier Ortensi ${ }^{2}$ \\ ${ }^{1}$ Thermal Fluid Systems Methods and Analysis \\ ${ }^{2}$ Reactor Physics Methods and Analysis
}

April 2021

Idaho National Laboratory Nuclear Science and Technology Idaho Falls, Idaho 83415

http://www.inl.gov

Prepared for the Office of Nuclear Regulatory Research U. S. Nuclear Regulatory Commission Washington, D. C. 20555 Task Order No.: 31310019F0015 
Page intentionally left blank 


\section{SUMMARY}

This report details the progress and activities of Idaho National Laboratory (INL) on the $\mathrm{Nu}-$ clear Regulatory Commission (NRC) project "Development and Modeling Support for Advanced Non-Light Water Reactors." Task 4b was completed for this report. INL developed a sample problem showing how to use Serpent 2 to calculate macroscopic cross sections for use in Griffin for a typical sodium fast reactor Unprotected Loss of Flow (ULOF) transient. The complicating factor is the relatively large axial gradient of the coolant (and hence fuel) temperature and its evolution during the transient. A 3D Griffin model of the Advanced Burner Test Reactor (ABTR) is coupled to the System Analysis Module (SAM) to perform the ULOF transient. The model includes various explicit feedback mechanisms for fast reactors, including Doppler, radial expansion from the displacement of the support plate, and axial expansion from the displacement of the fuel pins. The results for the ULOF transient are consistent with published values. We observed small effects in the transient results that arise from the superhomogenization equivalence correction of uniform and nonuniform temperature data sets, but they diminish as more dominant reactivity mechanisms are added to the model. Potential improvements to the neutronics model include: adding the differential control rod and sodium feedback mechanisms, implementing cross section re-homogenization based on the partial volume of the various materials, and enhancing the kinetics parameters. Furthermore, the fluids model only includes four subchannels to represent the entire active core due to performance limitations in SAM when attempting to model one subchannel per assembly. 


\section{ACKNOWLEDGEMENTS}

The authors would like to acknowledge the support from the following staff at Argonne National Laboratory: Rui Hu, Lin Zou, Guojun Hu, and T.K. Kim. 
Page intentionally left blank 


\section{CONTENTS}

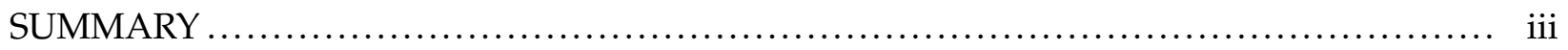

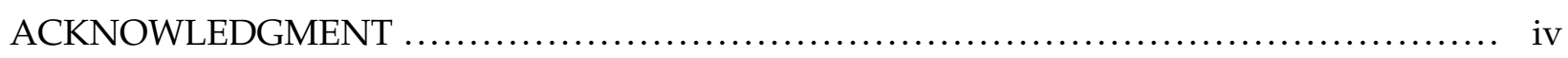

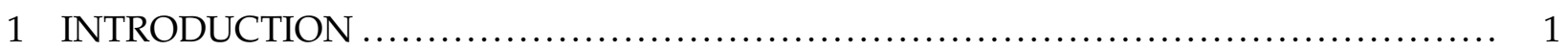

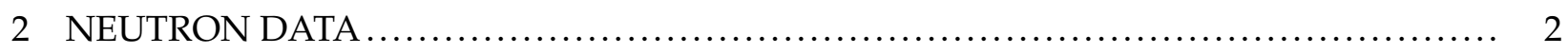

2.1 Overview of the Advanced Burner Test Reactor Core. $\ldots \ldots \ldots \ldots \ldots \ldots \ldots \ldots \ldots \ldots \ldots, 2$

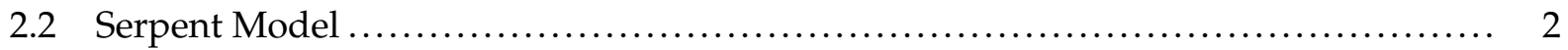

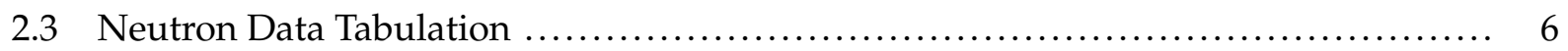

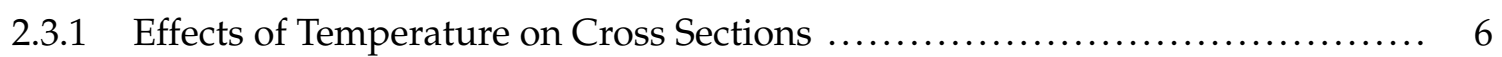

2.3.2 Reactivity Effects of Fuel Temperature Changes ........................... 7

$2.3 .3 \quad$ Impact of Temperature Profile on Neutronics $\ldots \ldots \ldots \ldots \ldots \ldots \ldots \ldots \ldots \ldots \ldots . \ldots \ldots$

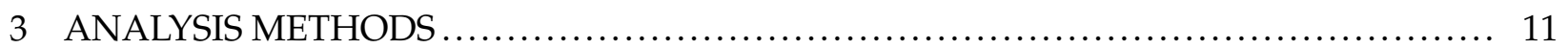

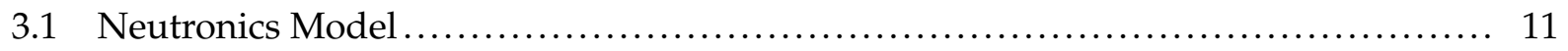

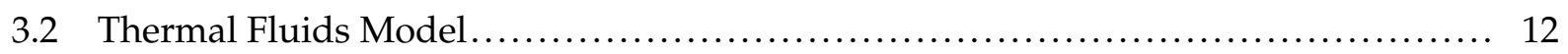

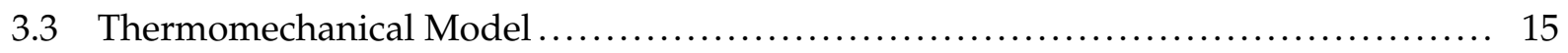

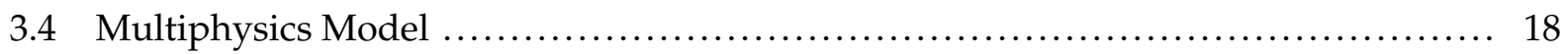

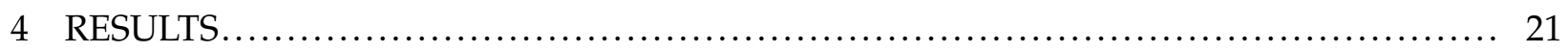

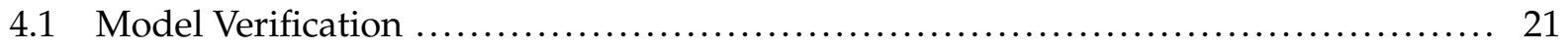

4.1.1 Model Based on Uniform Temperature Distributions ....................... 21

4.1.2 Model Based on Nonuniform Temperature Distributions . .................. 23

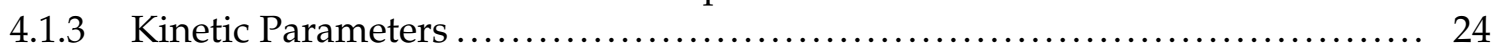

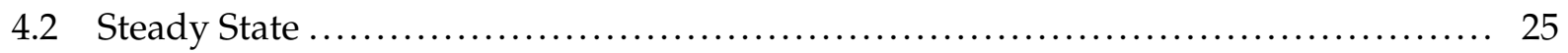

4.3 Unprotected Loss of Flow Transient . ....................................... 25

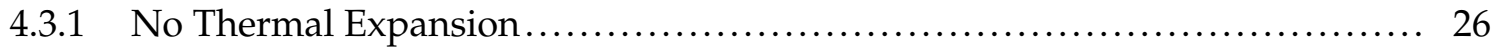

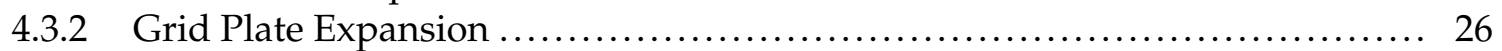

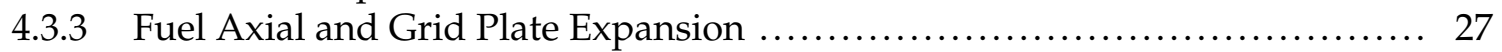

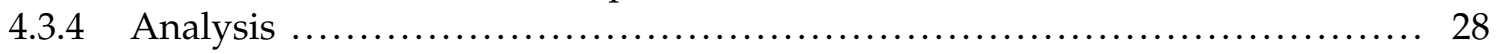

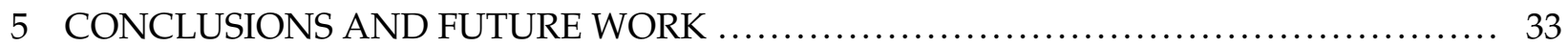

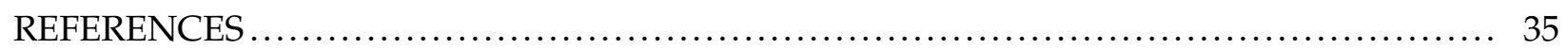




\section{FIGURES}

Figure 1. Radial core layout of ABTR benchmark problem $\ldots \ldots \ldots \ldots \ldots \ldots \ldots \ldots \ldots \ldots \ldots \ldots$

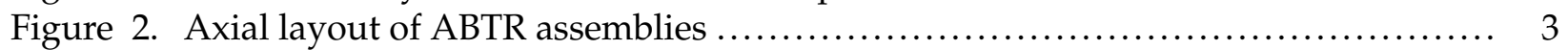

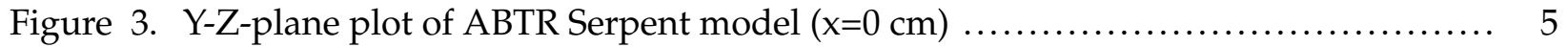

Figure 4. MCNP assembly power (normalized to unity) and relative error of Serpent solu-

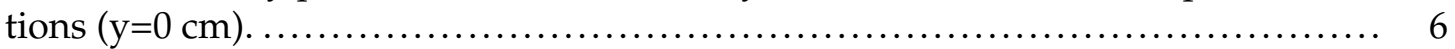

Figure 5. Fuel temperature distribution in the axial direction of ABTR core. $\ldots \ldots \ldots \ldots \ldots \ldots . . .6$

Figure 6. Comparison of total cross sections between uniform and distributed temperature

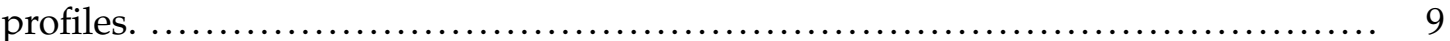

Figure 7. Comparison of assembly power (normalized to unity) distribution between uniform and distributed temperature profiles. $\ldots \ldots \ldots \ldots \ldots \ldots \ldots \ldots \ldots \ldots \ldots \ldots \ldots, 10$

Figure 8. ABTR neutronics mesh with 55,430 nodes and 54,810 wedge elements. Shown here are the cross-section zones. $\ldots \ldots \ldots \ldots \ldots \ldots \ldots \ldots \ldots \ldots \ldots \ldots \ldots \ldots \ldots \ldots, 11$

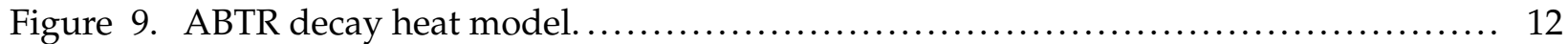

Figure 10. Schematic of the SAM-simulated system. ................................... 13

Figure 11. Thermomechanical mesh for the support plate. ................................ 16

Figure 12. Thermomechanical mesh for the fuel pin $\left(5 / 100^{t h}\right.$ scale $) . \ldots \ldots \ldots \ldots \ldots \ldots \ldots \ldots \ldots \ldots$

Figure 13. MOOSE coupling configuration for the multiphysics simulation.................. 18

Figure 14. The power quantity over the mass flux for the transient. $\ldots \ldots \ldots \ldots \ldots \ldots \ldots \ldots \ldots . \ldots \ldots$

Figure 15. Hot pool temperature for the various cases as a function of time. . . . . . . . . . . . . . 28

Figure 16. The relative difference between the uniform and nonuniform SPH corrections on

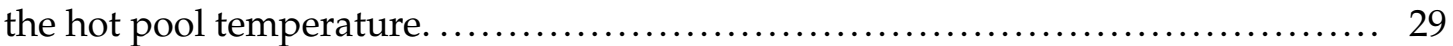

Figure 17. Temperature of the outlet of the inner core region versus time. . .................. 30

Figure 18. Relative difference between the outlet temperature for each transient.............. 31

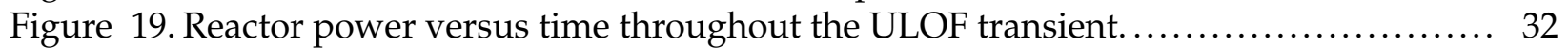

Figure 20. Relative difference between the power for each transient. $\ldots \ldots \ldots \ldots \ldots \ldots \ldots \ldots \ldots . . \ldots \ldots$ 


\section{TABLES}

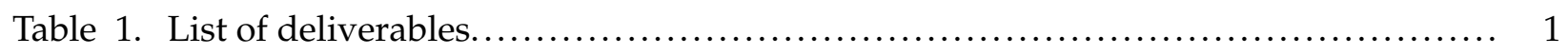

Table 2. Six-group structure used for Griffin calculations, based on ECCO 33 ............... 4

Table 3. Reactivity (\$) feedback of Advanced Burner Test Reactor (ABTR) $\ldots \ldots \ldots \ldots \ldots \ldots \ldots \ldots . \ldots$

Table 4. Comparison of the eigenvalue (k-eff) for different states of sodium................ 7

Table 5. Comparison of neutronic results for various temperatures used in cross sections of

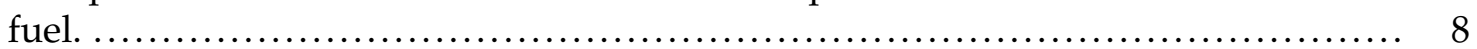

Table 6. Comparison of the k-eff between uniform and distributed temperature profiles ..... 9

Table 7. Maximum relative differences in 1-G XS between uniform and distributed temper-

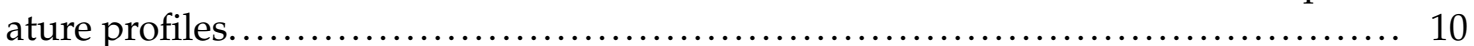

Table $8 . \quad$ BISON classes for constitutive physics models. . .................................. 16

Table 9. Fuel properties used in the BISON fuel simulation. ............................ 17

Table 10. Fundamental mode eigenvalues at each state point with a uniform temperature

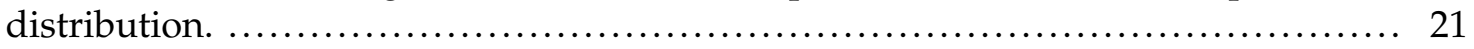

Table 11. \% Relative difference in the FoMs for the fission rate distribution at each state point

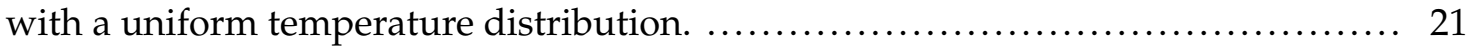

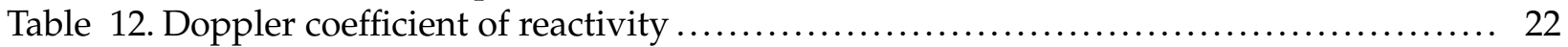

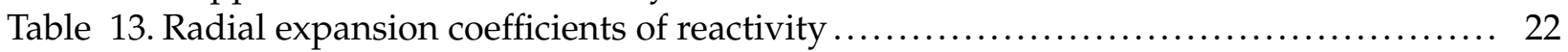

Table 14. Fundamental mode eigenvalues at each state point with a nonuniform tempera-

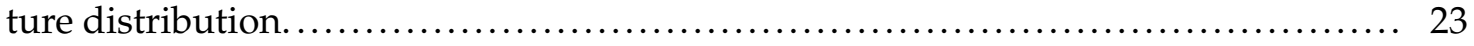

Table 15. \% relative difference in the FoMs for the power distribution at each state point

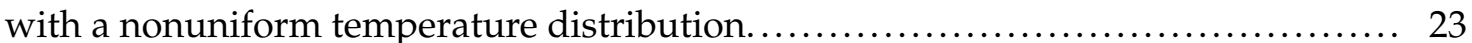

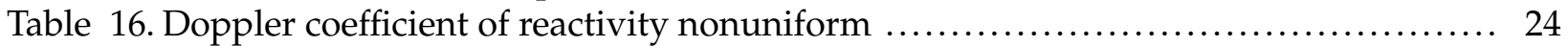

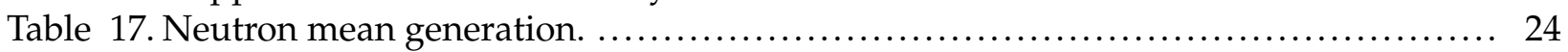

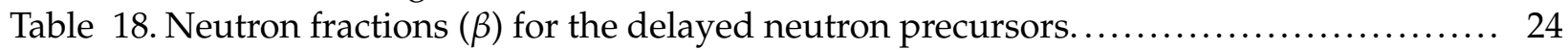

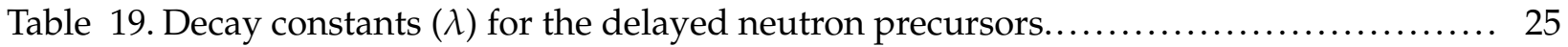

Table 20. Steady-state eigenvalues for each simulation with uniform and nonuniform corrections. 


\section{ACRONYMS}

ABTR Advanced Burner Test Reactor

ANL Argonne National Laboratory

BDBA Beyond Design Basis Accident

BOEC Beginning of Equilibrium Core

DRACS Direct Reactor Auxiliary Cooling System

FoM Figure of Merit

INL Idaho National Laboratory

MOOSE Multiphysics Object Oriented Simulation Environment

NRC Nuclear Regulatory Commission

SAM System Analysis Module

SPH Superhomogenization

ULOF Unprotected Loss of Flow 
Page intentionally left blank 


\section{INTRODUCTION}

This report details the progress and activities of Idaho National Laboratory (INL) in regard to the Nuclear Regulatory Commission (NRC) project "Development and Modeling Support for Advanced Non-Light Water Reactors."

Table 1 provides a summary of the tasks completed for this report. It matches the deliverable number, statement-of-work task, and (short) description of the deliverable.

Table 1: List of deliverables.

\begin{tabular}{ccl}
\hline $\begin{array}{c}\text { Deliverable } \\
\text { Number }\end{array}$ & $\begin{array}{c}\text { Statement of Work } \\
\text { Task }\end{array}$ & Description \\
\hline $4 \mathrm{~b}$ & $4 \mathrm{~b}$ & $\begin{array}{l}\text { Develop a sample problem showing how to use Serpent 2 to calculate } \\
\text { macroscopic cross sections for use in Griffin for a typical sodium fast re- } \\
\text { actor unprotected loss-of-flow transient (ULOF). The complicating fac- } \\
\text { tor is the relatively large axial gradient of the coolant (and hence fuel) } \\
\text { temperature and its evolution during the transient. }\end{array}$ \\
& &
\end{tabular}

The tasks completed for this report are:

- Task 4b: A 3D Griffin model of the Advanced Burner Test Reactor ABTR is coupled to System Analysis Module (SAM) to perform the ULOF transient. The model includes various explicit feedback mechanism for fast reactors, including Doppler, radial expansion from the displacement of the support plate, and axial expansion from the displacement of the fuel pins. The results for the ULOF transient are consistent with published values. We observed small effects in the transient results that arise from the Superhomogenization (SPH) equivalence correction of uniform and nonuniform temperature data sets, but they diminish as more dominant reactivity mechanisms are added to the model. 


\section{NEUTRON DATA}

This section discusses the preparation of neutron data with Serpent for use in Griffin transient analysis calculations of an ULOF event in a sodium-cooled fast reactor. Griffin is a Multiphysics Object Oriented Simulation Environment (MOOSE) [1] based reactor physics application that is jointly developed by Idaho National Laboratory (INL) and Argonne National Laboratory (ANL). A brief overview of the ABTR is presented in Section 2.1. The Serpent model is discussed in Section 2.2. and the preparation of the neutron data tabulation in Section 2.3 .

\subsection{Overview of the Advanced Burner Test Reactor Core}

Argonne National Laboratory (ANL) developed a benchmark problem [2] using the reference 250 MWt ABTR metallic core to assess their suite of fast reactor analysis codes. This benchmark problem is used here to demonstrate the application of Serpent to generate neutron data for use in modeling an ULOF in a sodium-cooled fast reactor with Griffin. Figure 1 shows the layout of the benchmark problem [2]. The core is composed of 54 driver, six fuel tests, three material tests, 78 reflectors, 48 shields, and seven primary and three secondary control assemblies. The compositions at the beginning of equilibrium core were used. Since the compositions of the test assemblies have not been determined, the material and fuel test locations were loaded with reflectors and driver assemblies, respectively. In this benchmark problem, we used the same composition for the primary and secondary control systems, and we positioned the absorber of all the control assemblies above the active fuel region. All assemblies have a pitch of $14.685 \mathrm{~cm}$ and an overall length of $341.66 \mathrm{~cm}$. Figure 2 shows the axial layouts of ABTR assemblies. Note that we implemented the benchmark problem under the operating condition that incorporated the thermal expansion of fuel and structure materials and irradiation swelling of metallic fuel. We used the heterogenous assembly model for this study, and the details of each assembly design are in Ref. [2].

\subsection{Serpent Model}

The Serpent code [3] developed at the VTT Technical Research Centre of Finland is a 3D continuous-energy Monte Carlo code with a built-in capability for generating homogenized multigroup constants. Serpent utilizes the universe-based geometry model, which allows for the model- 


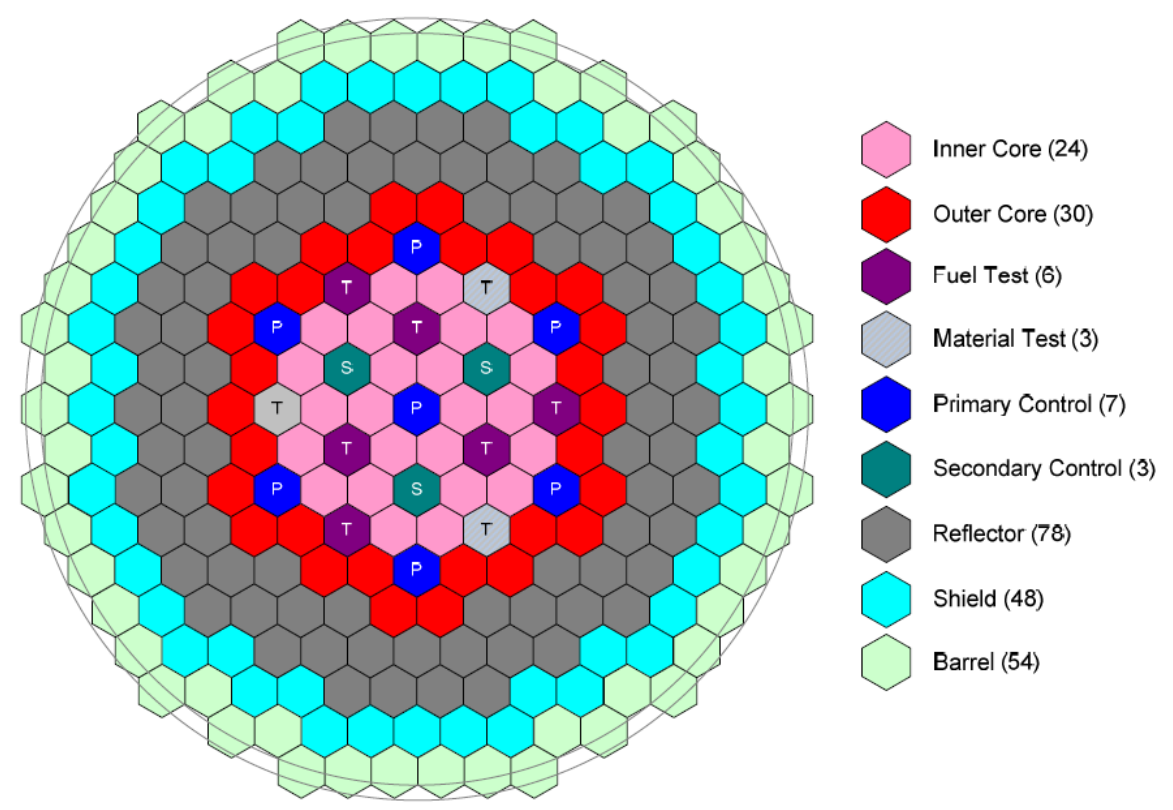

Figure 1: Radial core layout of ABTR benchmark problem [2].

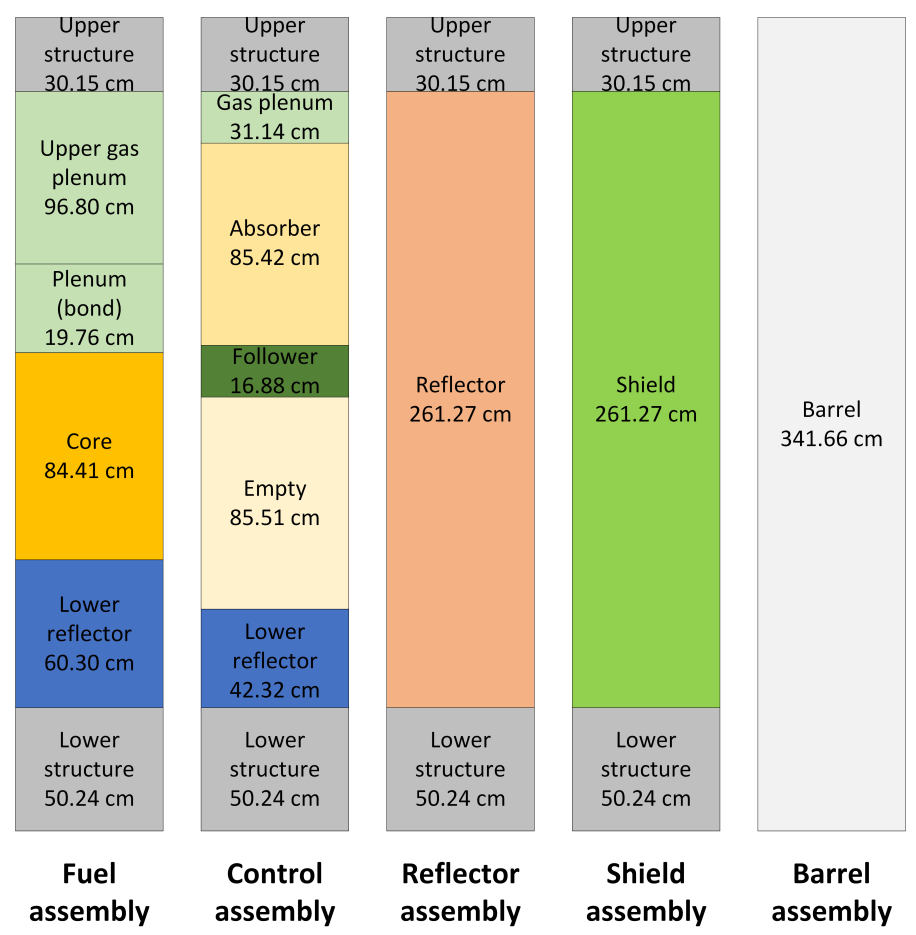

Figure 2: Axial layout of ABTR assemblies.

ing of complicated 3D geometries. A full-core ABTR Serpent model was developed for generating tabulated macroscopic cross sections and reference fluxes for using Griffin to compute the superhomogenization equivalence (SPH) factors [4]. In this study, we used SERPENT 2.1.31 along with 
the ENDF/B-VII.r1 cross-section data library. The Serpent calculations used 4 million histories per cycle and 50 inactive and 600 active cycles.

The initial ABTR Serpent model was obtained from the NRC. Additional modifications to the original input include:

- Cross-section library was updated from ENDF/B-VII.0 to ENDF/B-VII.r1.

- Natural elements, such as zirconium, molybdenum, etc., were updated with element isotopes in order to be consistent with the IDs used in the ENDF/B-VII.r1 library.

- We positioned the primary control rod bank above the active core, as specified in Ref. [2]. Figure 3 shows this positioning, where the absorber of control assemblies of both primary and secondary systems is positioned above the active core.

- We modified the inside radius of the core barrel from $113.5 \mathrm{~cm}$ to $115 \mathrm{~cm}$ to enable a better meshing between the peripheral assemblies and the core barrel. This initial spacing was very small and this change allows for a consistent mesh in Griffin calculations, while the thickness of barrel remains the same.

- We updated the core power to $250 \mathrm{MWt}$.

- This research used a six-group structure, based on the ECCO 33 group structure [5], for preparing the neutron data for Griffin calculations. The six-group structure is in Table 2 . The SPH correction enables us to depart from the traditional 33 group structure while preserving the important neutronic characteristics of the core.

Table 2: Six-group structure used for Griffin calculations, based on ECCO 33 groups structure [5].

\begin{tabular}{cccc} 
Group & Upper energy bound $(\mathrm{eV})$ & Group & Upper energy bound $(\mathrm{eV})$ \\
\hline 1 & $4.00000 \mathrm{E}+07$ & 4 & $4.08680 \mathrm{E}+04$ \\
2 & $1.35335 \mathrm{E}+06$ & 5 & $9.11880 \mathrm{E}+03$ \\
3 & $4.97870 \mathrm{E}+05$ & 6 & $3.35463 \mathrm{E}+03$
\end{tabular}

For comparison purposes, results obtained from our Serpent model were compared to MCNP results that were used to validate ANL's neutronics analysis tools [6]. To be consistent with the MCNP model, we adopted the carbon composition in B4C in the MCNP model. The barrel is 


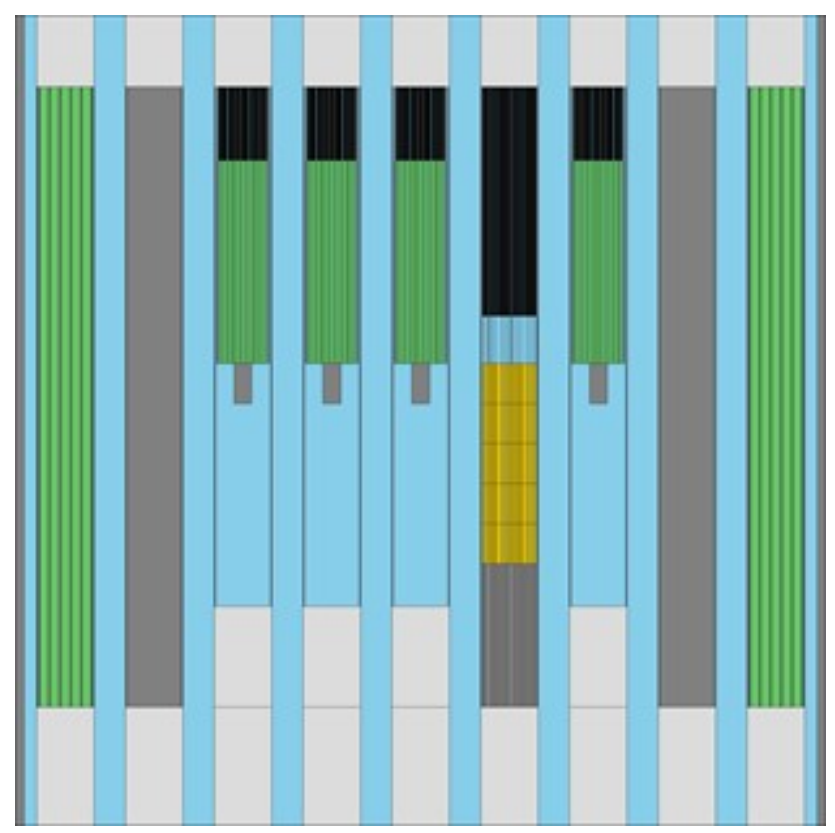

Figure 3: Y-Z-plane plot of ABTR Serpent model $(x=0 \mathrm{~cm})$

modeled as one ring of barrel assemblies in the Serpent model. For this comparison both the MCNP and Serpent models use cross-section libraries based on ENDF/B-VII.0 nuclear data. For the ABTR full-core model, the discrepancy in k-eff between the MCNP and Serpent calculations is $6 \mathrm{pcm}$. We also compared the assembly power distribution obtained from MCNP and Serpent. Figure 4 shows the MCNP power and the relative differences between MCNP and Serpent results for a one-third core. The power distribution is normalized to unity. The predicted power distribution agreed well between the two codes. The largest difference in power among the fuel assemblies is $0.58 \%$. 


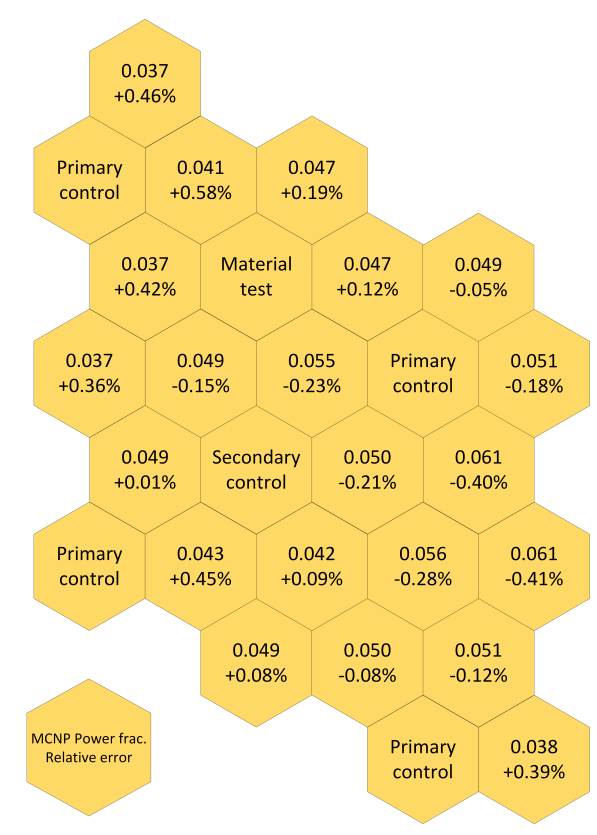

Figure 4: MCNP assembly power (normalized to unity) and relative error of Serpent solutions $(\mathrm{y}=0 \mathrm{~cm})$.

\subsection{Neutron Data Tabulation}

\subsubsection{Effects of Temperature on Cross Sections}

Section II.1.5 of [7] discusses the reactivity control requirements of the ABTR core. The reactivity control requirements include the temperature defect and expansion reactivity effects that result from changes in fuel height and density due to fuel temperature increase. Table 3 presents the role each component played on reactivity feedback for scenarios from hot full power to hot standby and hot standby to cold shutdown, which were calculated with an assumed refueling temperature of $478 \mathrm{~K}$. The effect of temperature on cross sections can be seen from Doppler and sodium density, where the Doppler effect is about nine and four times larger than the sodium density reactivity effect from hot full power to hot standby and from hot standby to cold shutdown, respectively. Table 4 compares the eigenvalue for different sodium temperatures and densities. The reference keff was calculated with the sodium at a core-averaged fluid temperature of $706 \mathrm{~K}$. Given the same density, the difference in k-eff between $756 \mathrm{~K}$ and $706 \mathrm{~K}$ is $2 \mathrm{pcm}$ and between $656 \mathrm{~K}$ and $706 \mathrm{~K}$ is $4 \mathrm{pcm}$, which are comparable to one and two statistical uncertainties, respectively. On the other hand, keeping the temperature constant, the difference in k-eff between the densities of $0.86 \mathrm{~g} / \mathrm{cc}$ (corresponding to $656 \mathrm{~K}$ ) and $0.85 \mathrm{~g} / \mathrm{cc}$ (corresponding to $706 \mathrm{~K}$ ) is $16 \mathrm{pcm}$ and between the den- 
sities of $0.84 \mathrm{~g} / \mathrm{cc}$ (corresponding to $756 \mathrm{~K}$ ) and $0.85 \mathrm{~g} / \mathrm{cc}$ is $25 \mathrm{pcm}$. The increased sodium density results in a softening of the neutron spectrum (increased epithermal flux fraction). Considering the difference in the impact of temperature on reactivity between Doppler and sodium density and the fact that the temperature feedback from Doppler is a direct effect of temperature on cross sections, while the sodium density reactivity effect results from both the reduced sodium density and cross sections, for this study, we only included the fuel temperature in the cross-section tabulation for representing temperature dependence.

Table 3: Reactivity (\$) feedback of \begin{tabular}{|l|l|l|}
\hline ABTR & Beginning of Equilibrium Core (BOEC) [7].
\end{tabular}

\begin{tabular}{ccc} 
Contribution & Hot full power to hot standby & Hot standby to cold shutdown \\
\hline Doppler & 0.18 & 0.14 \\
Sodium density & -0.02 & -0.04 \\
Axial expansion & 0.05 & 0.09 \\
Radial expansion & 0.46 & 0.89 \\
Total & 0.66 & 1.08
\end{tabular}

Table 4: Comparison of the eigenvalue (k-eff) for different states of sodium. The statistical error of the Serpent calculations is $\sim 2 \mathrm{pcm}$.

$\begin{array}{cccccc}\text { Sodium temperature }(\mathrm{K}) & 656 & 756 & 706 & 706 & 706 \\ \text { Sodium density }(\mathrm{g} / \mathrm{cc}) & 0.85 & 0.85 & 0.85 & 0.86 & 0.84 \\ \text { k-eff } & 1.03059 & 1.03053 & 1.03055 & 1.03071 & 1.03030 \\ \text { Delta k-eff }(\mathrm{pcm}) & +4 & -2 & - & +16 & -25\end{array}$

\subsubsection{Reactivity Effects of Fuel Temperature Changes}

Table 5 compares changes in neutronics parameters (k-eff, capture rate, total flux, and leakage rate) for different fuel temperatures. We computed the change in these parameters with respect to the result at $855 \mathrm{~K}$, which is the nominal operating temperature. The relative difference in total flux, capture, and leakage rates, between the temperature range of $600-1155 \mathrm{~K}$ and $855 \mathrm{~K}$, is less than $0.1 \%, 0.2 \%$, and $0.1 \%$, respectively. The impact of fuel temperature change on these neutronics parameters is somewhat weak compared to that of light-water reactors due to the resolved resonance self-shielding being less important in a fast neutron energy spectrum. Previous results [7] show that the 805-955 K temperature range should cover most the temperature range for fuels during an ULOF transient, but, to ensure conservatism in the cross-section tabulation, data at 600 $\mathrm{K}$ and $1155 \mathrm{~K}$ are added in the tabulation. 
Table 5: Comparison of neutronic results for various temperatures used in cross sections of fuel.

\begin{tabular}{ccccccc} 
Fuel temperature (K) & 600 & 805 & 855 & 905 & 955 & 1155 \\
\hline k-eff & 1.03168 & 1.03073 & 1.03055 & 1.03021 & 1.03007 & 1.02943 \\
Diff. in k-eff (pcm) & +113 & +18 & - & -34 & -48 & -112 \\
Rel. diff. in total flux (\%) & -0.07 & -0.01 & - & +0.00 & +0.01 & +0.05 \\
Rel. diff. in total capture rate (\%) & -0.18 & -0.03 & - & +0.05 & +0.08 & +0.18 \\
Rel. diff. in total leakage rate (\%) & -0.08 & -0.02 & - & +0.03 & +0.01 & +0.08
\end{tabular}

\subsubsection{Impact of Temperature Profile on Neutronics}

To estimate the impact of temperature profile on neutronics solutions, Serpent calculations were run with two fuel temperature axial profiles. We divided the active fuel region in the Serpent model into ten axial segments. For the uniform temperature profile, we applied the same temperature to the ten axial segments. For the distributed case, we obtained the axial profile of the temperature data from the thermal calculation. The temperature profile used in distributed cases is shown in Figure 5 .

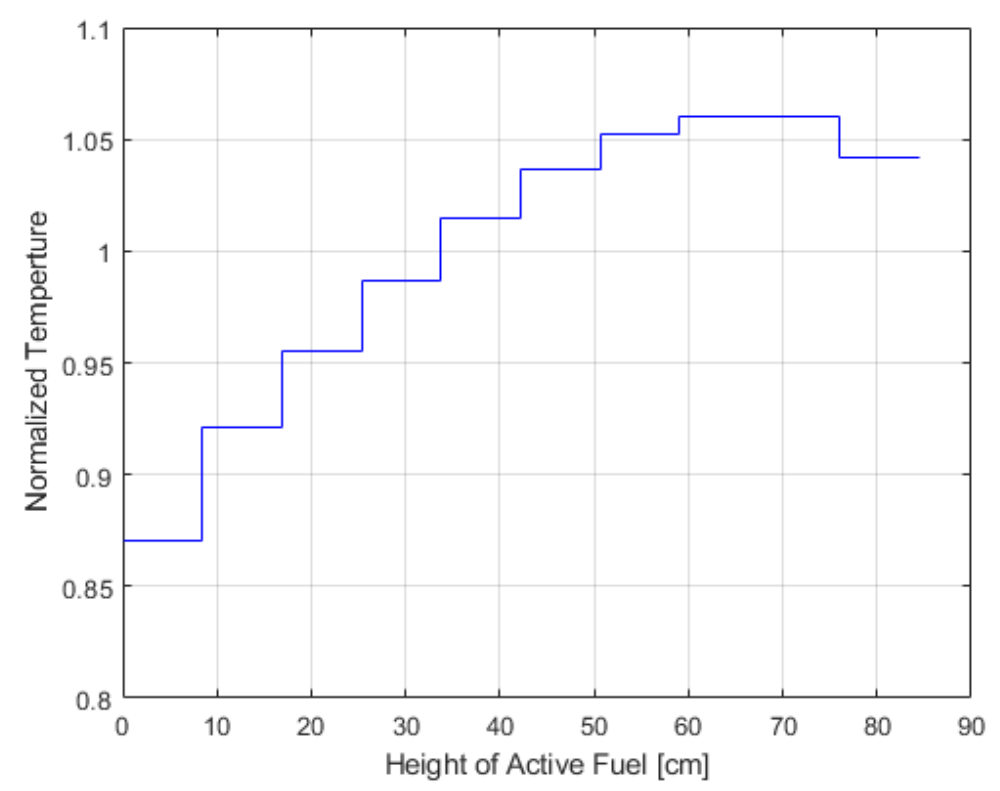

Figure 5: Fuel temperature distribution in the axial direction of ABTR core.

Table 6 compares the k-eff between two temperature profiles with average fuel temperatures of $600,805,855,905,955$, and 1155 K. For fuel temperatures of 855, 955, and 1155 K, the difference in k-eff between the two temperature profiles are around two statistical errors of the Serpent 
calculation. The largest difference between two temperature profiles among these temperature points is $19 \mathrm{pcm}$, where the average fuel temperature is $600 \mathrm{~K}$. However, as mentioned above, a fuel temperature of $600 \mathrm{~K}$ may not be a real case during a ULOF transient.

Table 6: Comparison of the k-eff between uniform and distributed temperature profiles. The statistical error of Serpent calculations is $\sim 2 \mathrm{pcm}$.

\begin{tabular}{ccccccc} 
Fuel temperature $(\mathrm{K})$ & 600 & 805 & 855 & 905 & 955 & 1155 \\
\hline Uniform temperature & 1.03168 & 1.03073 & 1.03055 & 1.03021 & 1.03007 & 1.02943 \\
Distributed temperature & 1.03187 & 1.03080 & 1.03058 & 1.03029 & 1.03009 & 1.02946
\end{tabular}

Figure 6 compares the one-group total cross section of fuels between two temperature profiles for fuels in inner, outer core and test locations, with an average fuel temperature of $855 \mathrm{~K}$. As the figure shows, the differences in the total cross section between two temperature profiles are insignificant for all the fuels.

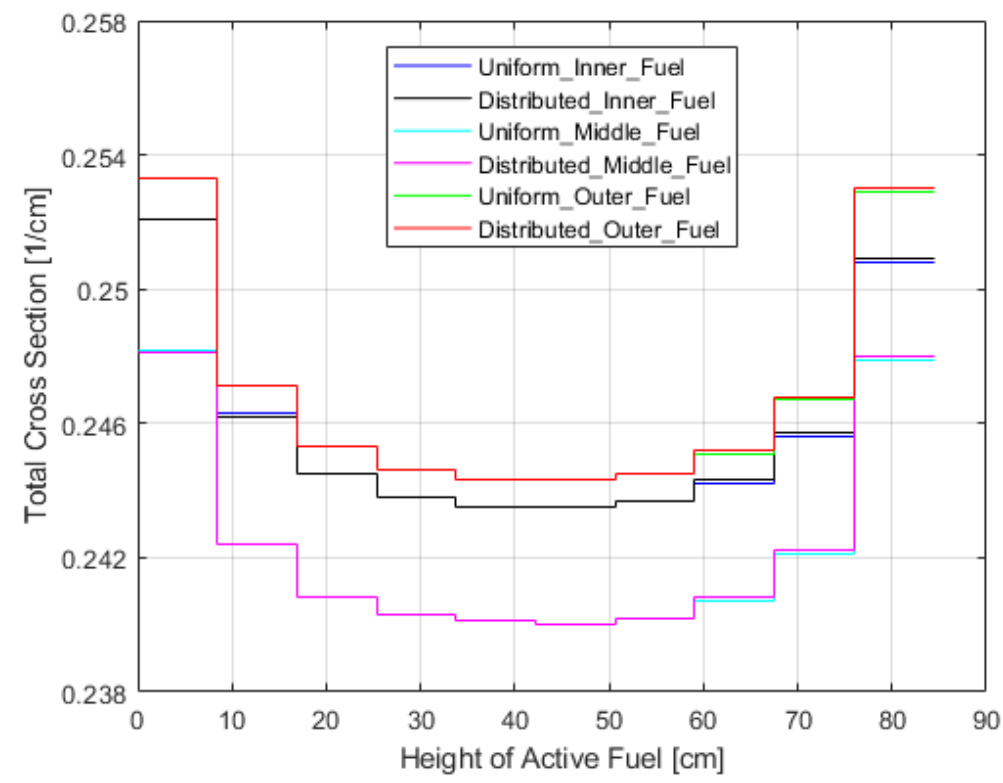

Figure 6: Comparison of total cross sections between uniform and distributed temperature profiles.

Table 7presents the maximum relative error in the one-group cross sections between two temperature profiles for the ten axial segments. The maximum relative error in total, capture, and fission cross section is $0.05 \%, 0.28 \%$, and $0.05 \%$, respectively. Figure 7 shows the power distribution of the case with a uniform temperature profile and the relative differences between uniform 
and distributed temperature profiles. The power distribution of the one-third core is normalized to unity. The calculated power distribution agreed well between two temperature profiles. The largest difference in power among fuel assemblies is $0.06 \%$. The above results indicate that the impact of temperature profile on neutronics is marginal. But, considering that the SPH factors could be somewhat different between two temperature profiles, the cross sections and SPH factors are generated with both temperature profiles. Note that, in this study, only region-wise cross sections were generated (i.e., a set of fuel cross sections was generated by averaging the fuel cross section in the ten axial segments), but the reference solutions should be able to be reproduced with $\mathrm{SPH}$-corrected cross sections, where the SPH factors were generated for each axial segment.

Table 7: Maximum relative differences in 1-G XS between uniform and distributed temperature profiles.

\begin{tabular}{cccc} 
& Total & Capture & Fission \\
\hline Inner-core fuel & $0.05 \%$ & $0.20 \%$ & $0.03 \%$ \\
Test fuel & $0.05 \%$ & $0.16 \%$ & $0.05 \%$ \\
Outer-core fuel & $0.05 \%$ & $0.28 \%$ & $0.03 \%$
\end{tabular}

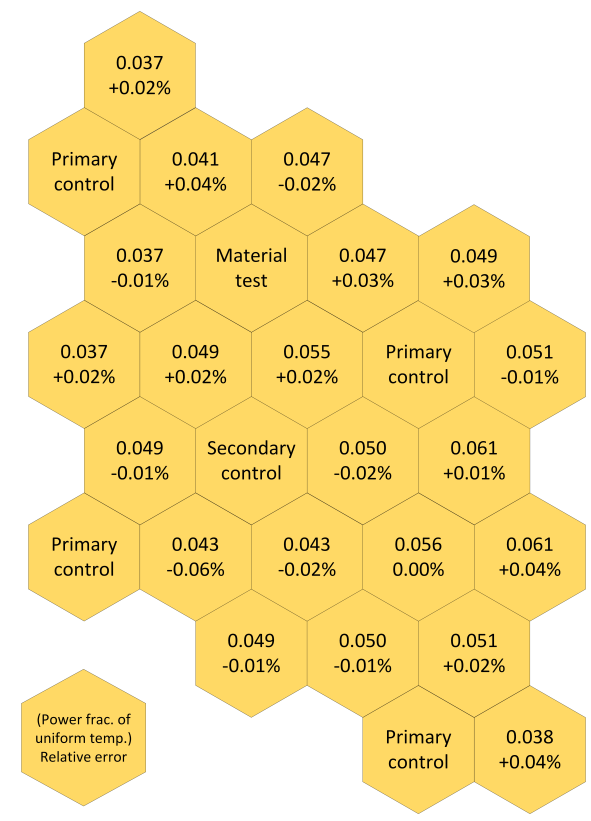

Figure 7: Comparison of assembly power (normalized to unity) distribution between uniform and distributed temperature profiles. 


\section{ANALYSIS METHODS}

\subsection{Neutronics Model}

The Griffin model of the ABTR is assembly-homogenized and intended for use in SPH-diffusion [4] calculations. The mesh is considerably coarse, as shown in Figure 8, with element heights near 9$10 \mathrm{~cm}$. The total element count is 54,810 elements. The model includes 45 cross-section regions and 2,942 SPH equivalence zones.

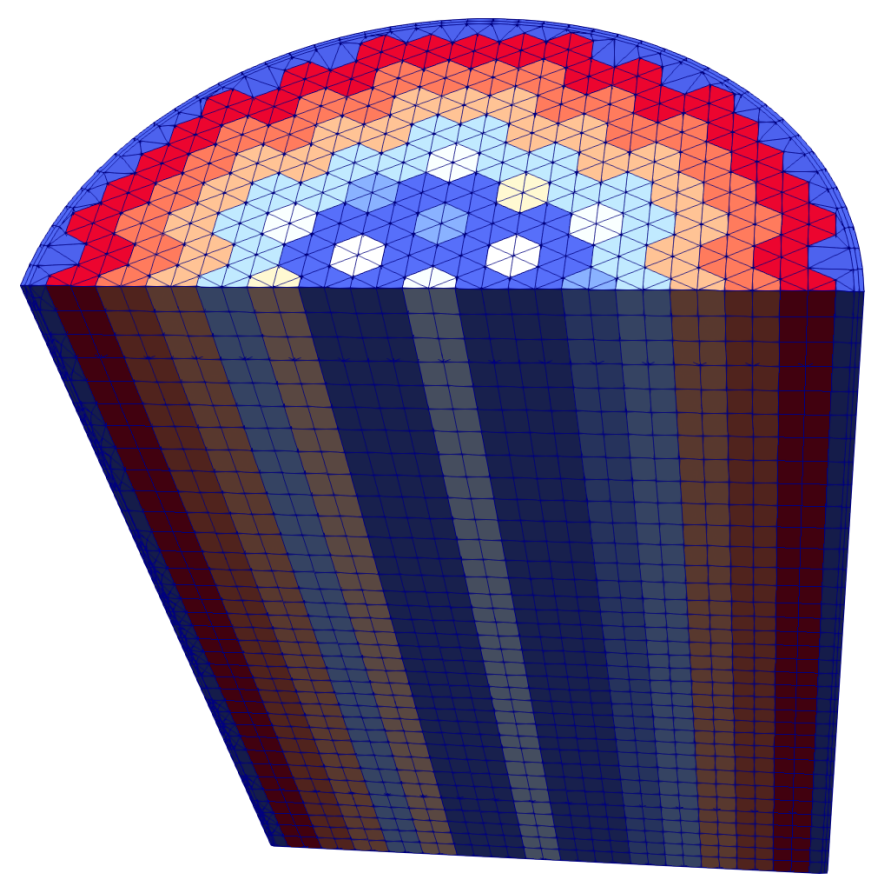

Figure 8: ABTR neutronics mesh with 55,430 nodes and 54,810 wedge elements. Shown here are the cross-section zones.

Comparisons between Griffin and Serpent are based on fission reaction rates within each SPH region. To facilitate these comparisons we introduced the definition of the root mean squared (RMS) error, minimum, and maximum error as the Figure of Merit (FoM):

$$
\begin{aligned}
& \epsilon_{\mathrm{RMS}}=\sqrt{\frac{1}{M} \sum_{m=1}^{M}\left(\left(1-\frac{R_{m}}{L_{m}}\right) * 100\right)^{2}} \\
& \epsilon_{\max \mid \min }=\max _{m=1, . ., M} \mid \min _{m=1, . ., M}\left[\left(1-\frac{R_{m}}{L_{m}}\right) * 100\right]
\end{aligned}
$$


where,

$M$ is the total number of SPH regions in the mesh $(2,942)$

$R_{m}$ is the integral fission reaction rate over the SPH equivalence region $m$ computed with Griffin

$L_{j}$ is the integral fission reaction rate over the $\mathrm{SPH}$ equivalence region $m$ computed with Serpent.

The local decay heat power in Griffin is computed with the steady-state power distribution and the time-dependent decay heat power fraction obtained from a Serpent assembly model. This approximate model will be improved in the future with the ANSI/ANS-5.1-2014 standard [8]. A comparison of the Serpent and Griffin fractional decay heat as a function of time is in Figure 9

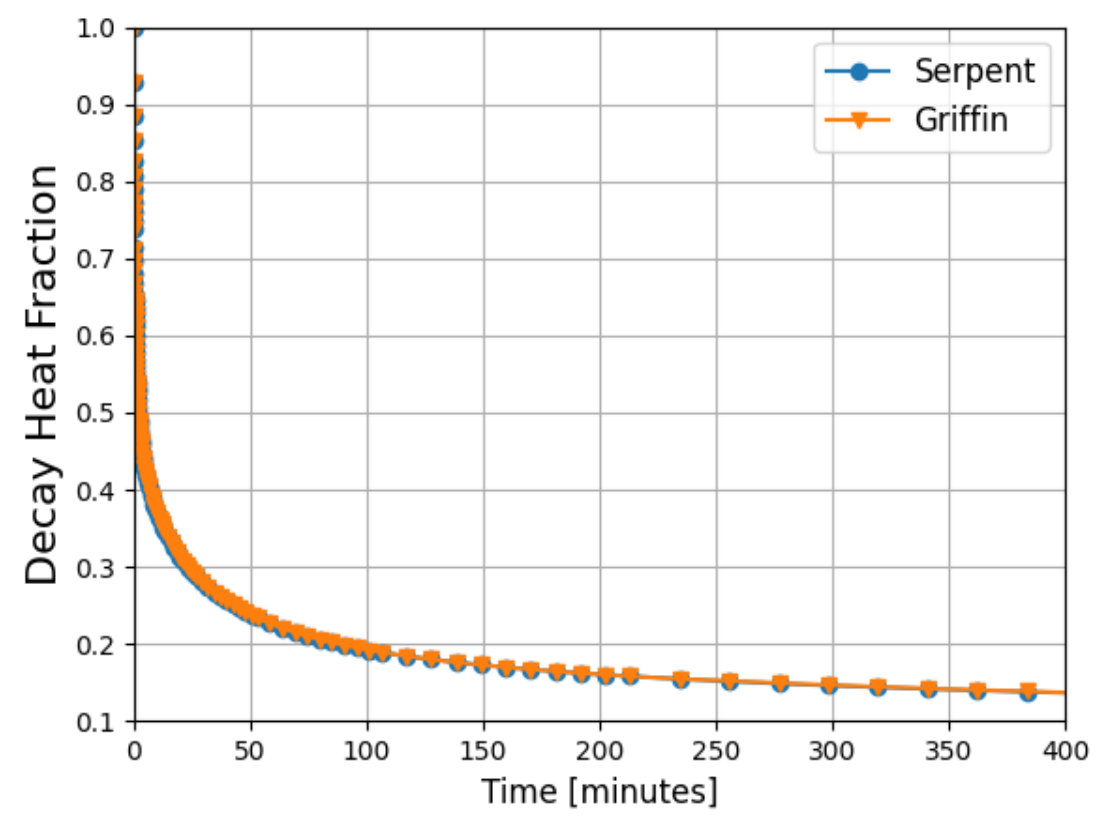

Figure 9: ABTR decay heat model.

\subsection{Thermal Fluids Model}

The thermal fluids system was modeled with SAM [9]. SAM is a systems analysis code that allows auxiliary equipment to be modeled to influence the response of the reactor. SAM breaks this equipment down into items called components that can be coupled together to fully describe the system. There are several major components in the ABTR that we will describe in detail as they are 
placed into the model. A schematic is presented in Figure 10 so that the appropriate connections can be seen. We obtained the specifications used in the SAM input from [10], which built on [7]. The major components in the model were the core, the inlet plenum, the outlet plenum, a cold pool with a cover gas, three heat exchangers, and two pumps. The three heat exchangers are the Direct Reactor Auxiliary Cooling System DRACS) heat exchanger, the intermediate loop heat exchanger, and the secondary loop heat exchanger. The two pumps are the primary loop pump and the secondary loop pump.

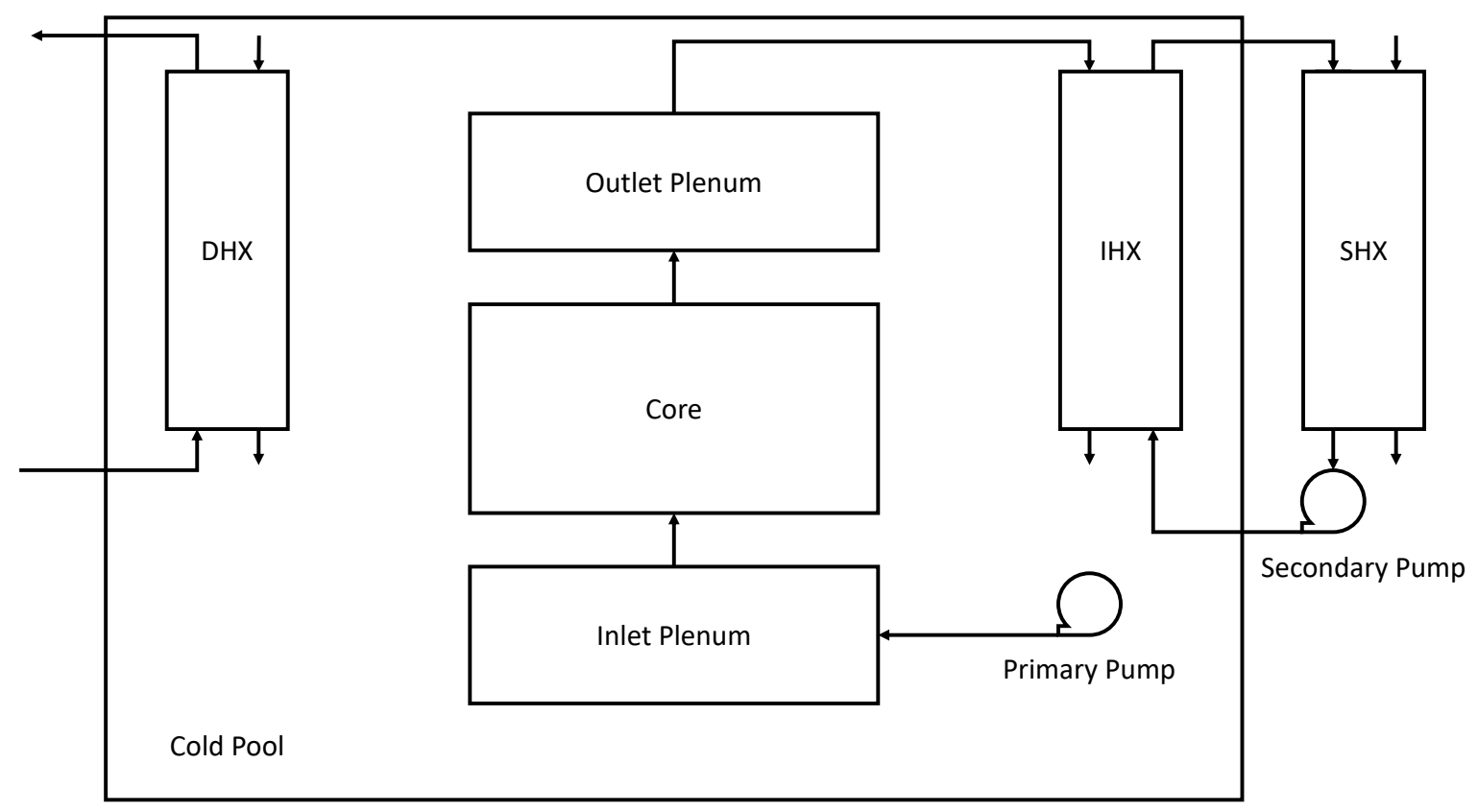

Figure 10: Schematic of the SAM-simulated system.

The core can be modeled in various ways, depending on the desired information, the coupling scenario, and the desired speed of the computation. Currently, four channels are in place to represent the core. These channels represent an inner core region, an outer core region, and a test fuel region with the last channel representing the reflector. It is possible to include more channels in the SAM simulation, but the computational performance suffers dramatically. Without an efficient way to solve the simulation in parallel, it is not realistic to use many channels.

The inlet plenum is modeled with a PBVolumeBranch component in SAM. A PBVolumeBranch is a branch with volume so that energy and mass conservation can be applied. It takes the pump 
discharge as an input, and its output is provided to the core.

The outlet plenum or hot pool is modeled as a PBLiquidVolume component. Unlike the PBVolumeBranch, this can have a varying liquid level based on imbalances between flows into and out of the volume and the cover gas pressure. This pool is part of the pool type setup for the ABTR and has been divided to account for the core outlet region and core inlet region differences. The outlet plenum takes the core outlet information as an input and provides an output to the intermediate loop heat exchanger.

The cold pool is also modeled as a PBLiquidVolume component. The cold pool is coupled to the same cover gas and takes the outlets of the two heat exchangers in the pool as an input and provides outputs to the DRACS heat exchanger and the pump inlet for the primary pump.

The DRACS heat exchanger is modeled as a PBHeatExchanger component. This component simplifies a heat exchanger down to a flow area and length for both sides. It then takes in heat transfer surface area densities to scale the fluid volume to the representative heat exchanger surface area. Both its inlet and outlet for the primary side are connected to the cold pool. Its secondary side is driven by a function-based flow rate inlet and a pressure outlet condition.

The intermediate loop heat exchanger is also a PBHeatExchanger component. The primary side receives its input from the outlet plenum and discharges directly into the cold pool. The secondary side is coupled to the secondary loop heat exchanger. The secondary side has a flow rate drive by a pump in a closed loop configuration.

The secondary loop heat exchanger is also a PBHeatExchanger component. The primary side receives the Intermediate loop heat exchanger outputs and it discharges to the secondary loop pump. The secondary side is modeled similarly to the DRACS loop, with a function-driven flow provided as an input and pressure outlet boundary.

The two pumps are modeled as PBPump components. The PBPump component is a branch component that models pumping power and energy conservation in the flow through the component. The pump head can be specified according to a function and allows for coast downs to be simulated. Each of these pumps has their own pump head function specified in the input. The primary side pump takes the cold pool as an inlet and discharges to the inlet plenum. The secondary pump takes the secondary loop heat exchanger primary side outlet as an input and discharges to the intermediate loop heat exchanger. 
Piping is only accounted for in the intermediate loop and the actual core structure. The core structure needs these piping components to account for the inlet region pressure drop and the outlet region pressure drop, which is a significant portion of the total pressure drop. The intermediate loop also accounts for the piping infrastructure for the same reason as the piping connecting the heat exchangers is a significant portion of the total pressure drop.

\subsection{Thermomechanical Model}

A 2D BISON thermomechanical model of the 316 stainless-steel support plate is included to compute the mesh displacement and the consequent effect on the core assembly pitch. We assumed a hexagonal pitch since no detailed design information is available. The mesh is shown in Figure 11. The 2D displacement field is transferred to the Griffin application and projected in the axial direction as a uniform field (i.e., it is constant in the $\mathrm{z}$ direction). This is a rather crude thermal expansion feedback model model that assumes:

- that all homogenized materials are displaced jointly, uniform re-homogenization, when it is known that the density changes are material dependent and the sodium fills or is extruded from various volumes with the material displacements.

- that a single value of the temperature is sufficient to solve the tensor mechanics stress and strain fields, as well as the displacements. This temperature is set to the inlet coolant temperature.

Table 8 provides a list of the various constitutive models used in the calculation. The model assumes that all elastic strain and stress is recoverable, thus ComputeFiniteStrainElasticStress computes the elastic stress for an incremental formulation, both incrementally small and incrementally finite strain formulations. The SS316ThermalExpansionEigenstrain class computes the eigenstrain due to thermal expansion using a function that describes the mean thermal expansion as a function of temperature. The SS316ElasticityTensor class computes the Young's modulus and Poisson's ratio using relations as a function of temperature. Zero displacement conditions are imposed on two nodes, one $x$ and one $y$, to prevent the translation and rotation of the thermomechanics model during the calculation. 


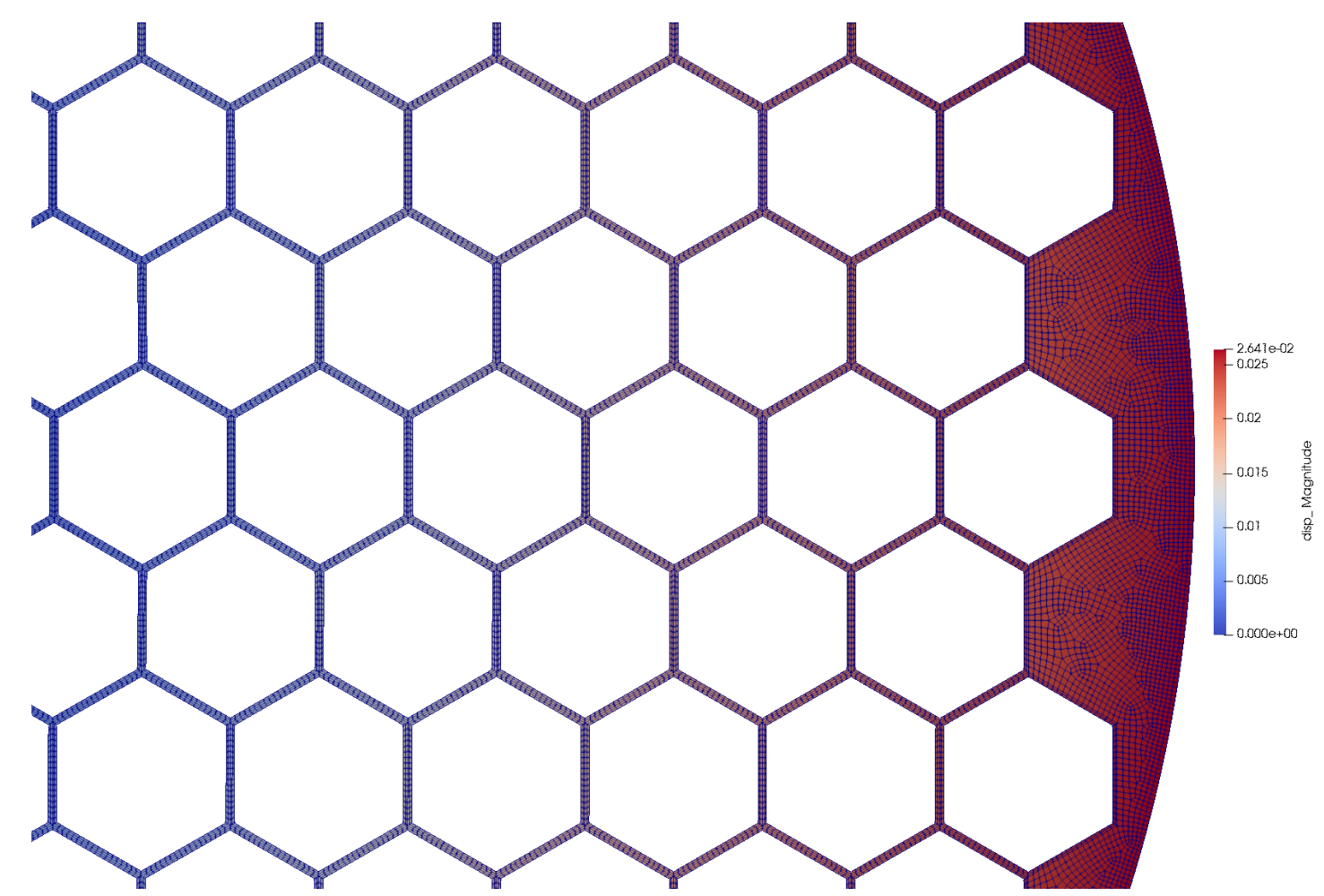

Figure 11: Thermomechanical mesh for the support plate.

Table 8: BISON classes for constitutive physics models.

\begin{tabular}{l|c} 
Model & Class \\
\hline Elastic stress & ComputeFiniteStrainElasticStress \\
Thermal expansion & SS316ThermalExpansionEigenstrain \\
Elasticity tensor & SS316ElasticityTensor
\end{tabular}

The fuel expansion was handled by a 3D BISON thermomechanical model of the fuel pin. The pin consists of a cylindrical fuel region and an annular clad region. The fuel pin is 0.8441-m long, with a fuel diameter of $0.00696 \mathrm{~m}$ and a clad thickness of $0.00052 \mathrm{~m}$. This is a relatively simple model, and it assumes that the two layers are attached in expansion. There is no gap, so no mechanical contact detection is necessary. The base of the fuel is assumed to be fixed in place with a zero displacement boundary conditions. Two additional conditions were added to fully constrain the problem to prevent it from rotating or translating in the $\mathrm{x}$ and y planes.

The fuel and clad both use constant properties in the thermomechanics calculations. These values were used from prior work from [10] and are outline in Table 9.

The mesh used for this simulation is relatively simple. It is a cylinder mesh in Cubit [11]. We could not use a 2D axisymmetric simulation because it cannot be simulated along the $\mathrm{z}$ axis; 
Table 9: Fuel properties used in the BISON fuel simulation.

\begin{tabular}{l|c} 
Property & Value \\
\hline Fuel Youngs modulus & $2.8 \mathrm{E} 10$ \\
Fuel Poissons ratio & 0.3 \\
Fuel thermal expansion coefficient & $1.76 \mathrm{E}-5$ \\
Fuel stress-free temperature & 293.15 \\
Clad Youngs Modulus & $1.5 \mathrm{E} 11$ \\
Clad Poissons ratio & 0.3 \\
Clad thermal expansion coefficient & $1.4 \mathrm{E}-5$ \\
Clad stress-free temperature & 293.15
\end{tabular}

therefore, the transfers could not get the displacement back to Griffin correctly. This is a limitation in MOOSE that results in only the $x-y$ plane being used for axisymmetric simulations. 3D was then required to ensure the displacements could be accurately transferred. The mesh was created by meshing a circle and an annulus then extruding that mesh in the axial direction. This can be done easily in Cubit, and there are simple automatic meshers that develop quality meshes on circular faces. The mesh can be seen in Figure 12, where the red is the clad and the gray is the fuel.

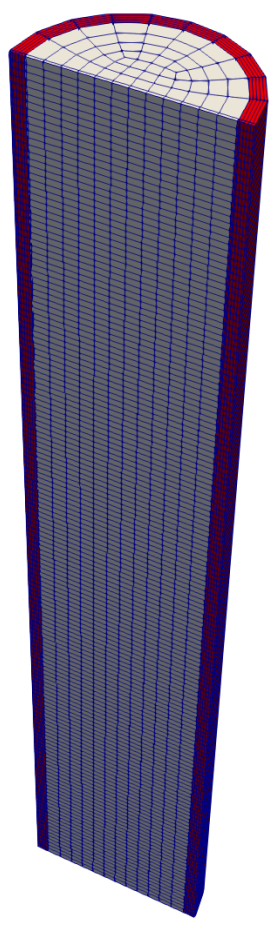

Figure 12: Thermomechanical mesh for the fuel pin $\left(5 / 100^{\text {th }}\right.$ scale).

In the future, a gap could potentially be added to model how that gap changes as the simulation progresses. But, adding a mechanical contact algorithm complicates the simulation and, in 
this case, would not substantially affect the result as the radial expansion dominates core reactivity effects. Any changes to core axial behavior would be additive to the axial portion of the feedback.

\subsection{Multiphysics Model}

To couple these models together into a multiphysics simulation, we employed the MOOSE multi-app system. The MOOSE multi-app system allows these models to be coupled in a simple manner. For this analysis, Griffin is the main app calculating the primary neutronics behavior and establishing the transient power changes. The thermomechanical models and the thermal fluids model are coupled through transfers. These transfers take important quantities and communicate them between the main app and the sub-apps. How the transfers are performed and the assumptions made in the transfer could affect the results of the simulation. A diagram of the multi-app system setup is presented in Figure 13 which shows the execution sequence and the specific transfers.

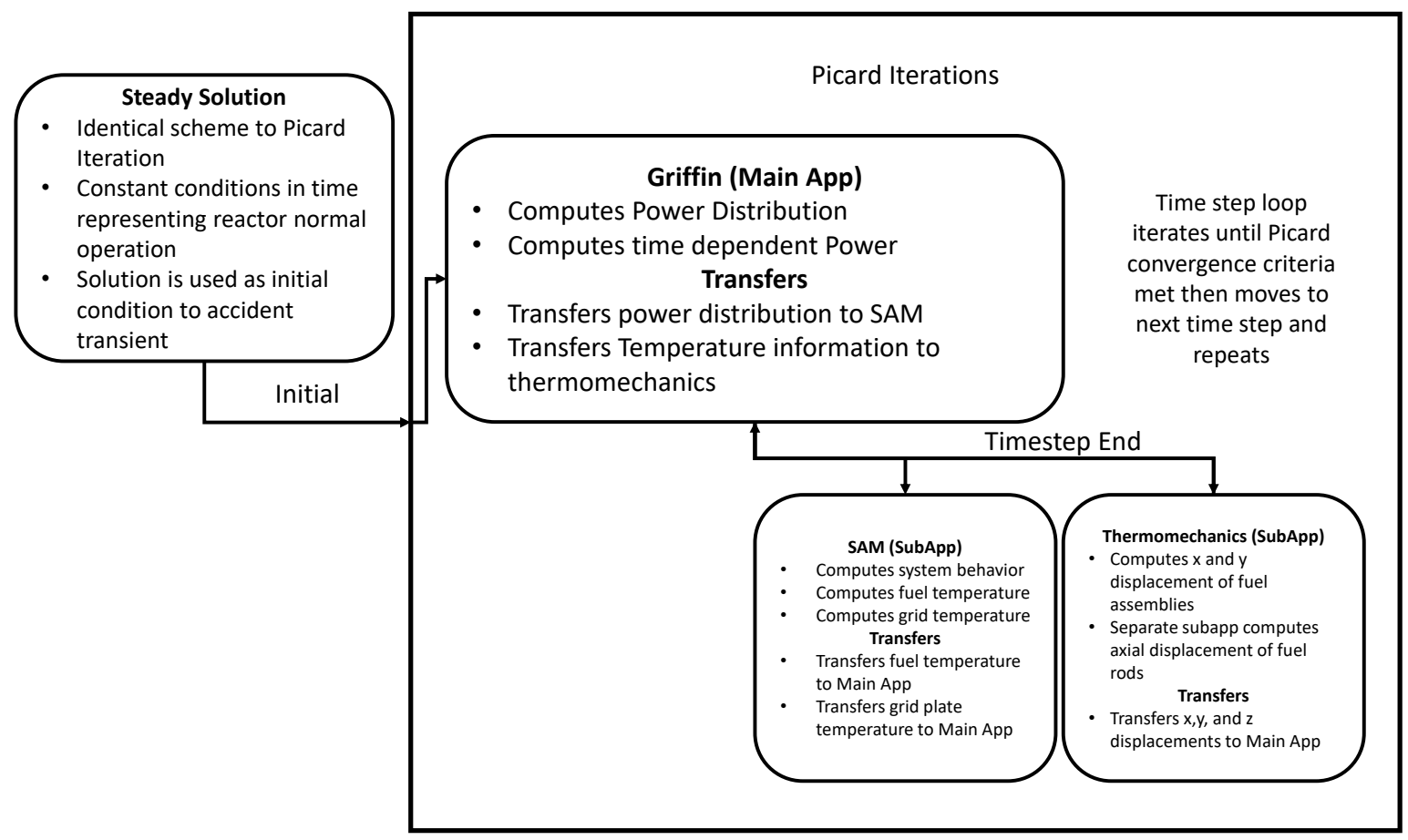

Figure 13: MOOSE coupling configuration for the multiphysics simulation.

The first sets of transfers are between Griffin and SAM. Griffin is responsible for calculating power profiles and the total core power at any time step. SAM is responsible for calculating 
fuel temperature and requires a power density. To accomplish this, a conservative transfer is performed using a layered average formulation. The layered averaging calculates the average power density in a specified slice along a specified axis, in this case the $\mathrm{z}$ axis. The layered average also has block-restricted capabilities, allowing power density to be transferred based on the subchannel configuration set up in SAM. Block restriction simply means the procedures are only carried for mesh elements that have the same identifier as specified in the input. The conservative portion is a feature that allows the transfer to remain conservative based on post-processors that are defined in the main and sub-app. For power based transfers, it is desirable to conserve power, and so post-processors were created to ensure power was conserved.

Once SAM calculated the temperature profiles in the fuel, the temperature could then be transferred back to Griffin to update the fuel temperature for each region. The fuel temperature has an important effect on reactivity feedback, so it is important to determine the temperatures in an accurate manner. Sodium temperature is not transferred because the SPH factors are generated for the fuel temperature dependence and not the coolant in this study. A layered average is also used to transfer temperature in a non-conservative way. With conservative transfers post processors are used to scale the local values to ensure integral quantities like power remain the same in both apps. When the transfer is non-conservative, the values are transferred without being scaled. For certain quantities like temperature and displacement conservation is not needed. There is also a lower plenum temperature that is transferred for the lower grid plate expansion calculation. This is necessary because a large portion of negative reactivity during these transients is caused by increased leakage from the core structural material expanding.

MOOSE executes transfers to multi-apps and from multi-apps at the same time. So when Griffin transfers information to a multi-app, it will transfer all information in the "to" direction. This is important because that means the temperature information, as calculated by SAM, is lagged one iteration before it makes it to the thermomechanical calculation. With Picard iterations, the time step is iterated until converged, but this lagging of variables could be problematic. The thermomechanical calculation is sent the lower grid temperature information from Griffin and then, once the thermomechanical calculation is complete, the displacements in the $\mathrm{x}$ and $\mathrm{y}$ plane are transferred back. The axial expansion is calculated from a separate thermomechanical multi-app that simulates a fuel pin. Both use interpolation transfers to get temperature information to the 
multi-app and to get displacement information from the multi-app.

This allows the transient to be calculated accurately and with real physics wherever possible. The systems code is used to obtain balance-of-plant behavior during transients and during steady state. And the thermomechanics and the Griffin are used to calculate thermal expansion behavior of the core and the power transient behavior of the system, respectively. 


\section{RESULTS}

\subsection{Model Verification}

The verification of the Griffin model is an important step before proceeding with transient analysis. The various state points used for the cross sections and SPH tabulations are verified for accuracy. The verification of the uniform and nonuniform temperature fields are in Sections 4.1.1 and 4.1 .2 , respectively.

\subsubsection{Model Based on Uniform Temperature Distributions}

A comparison of the fundamental mode eigenvalues for each state point between the reference Serpent and Griffin calculations is shown in Table 10, In all cases, Griffin reproduces the eigenvalue within the statistical uncertainty of the Monte Carlo reference. The accuracy of the solution is confirmed by examining the fission rate in all $\mathrm{SPH}$ regions from Table 11 . The maximum relative difference in the fission rate in any SPH zone is $0.00683 \%$ of the reference Monte Carlo.

Table 10: Fundamental mode eigenvalues at each state point with a uniform temperature distribution.

\begin{tabular}{c|c|c|c|c|c} 
Case & $\begin{array}{c}\text { Temp. } \\
{[K]}\end{array}$ & $\begin{array}{c}\text { Serpent } \\
k_{\text {eff }}\end{array}$ & $\begin{array}{c}\text { Serpent } \\
\text { uncert }\end{array}$ & $\begin{array}{c}\text { Griffin } \\
k_{\text {eff }}\end{array}$ & $\begin{array}{c}\text { Difference } \\
{[p c m]}\end{array}$ \\
\hline 1 & 600 & 1.03168 & $1.60 \mathrm{E}-05$ & 1.03168 & -0.08 \\
2 & 805 & 1.03073 & $1.60 \mathrm{E}-05$ & 1.03073 & -0.07 \\
3 & 855 & 1.03055 & $1.60 \mathrm{E}-05$ & 1.03055 & -0.07 \\
4 & 905 & 1.03021 & $1.60 \mathrm{E}-05$ & 1.03021 & -0.07 \\
5 & 955 & 1.03007 & $1.60 \mathrm{E}-05$ & 1.03007 & -0.17 \\
6 & 1155 & 1.02943 & $1.60 \mathrm{E}-05$ & 1.02943 & -0.07
\end{tabular}

Table 11: \% Relative difference in the FoMs for the fission rate distribution at each state point with a uniform temperature distribution.

\begin{tabular}{c|c|c|c|c} 
Case & $\begin{array}{c}\text { Temp } \\
{[K]}\end{array}$ & RMS & Max. & Min. \\
\hline 1 & 600 & $2.44 \mathrm{E}-03$ & $5.56 \mathrm{E}-03$ & $4.50 \mathrm{E}-06$ \\
2 & 805 & $2.85 \mathrm{E}-03$ & $5.86 \mathrm{E}-03$ & $2.17 \mathrm{E}-06$ \\
3 & 855 & $3.39 \mathrm{E}-03$ & $6.83 \mathrm{E}-03$ & $7.59 \mathrm{E}-07$ \\
4 & 905 & $2.50 \mathrm{E}-03$ & $5.57 \mathrm{E}-03$ & $7.03 \mathrm{E}-06$ \\
5 & 955 & $2.20 \mathrm{E}-03$ & $5.15 \mathrm{E}-03$ & $4.17 \mathrm{E}-06$ \\
6 & 1155 & $2.47 \mathrm{E}-03$ & $5.46 \mathrm{E}-03$ & $2.01 \mathrm{E}-06$
\end{tabular}


The Doppler coefficients of reactivity computed with Griffin are included in Table 12 . The predicted values are consistent with the reported value of -0.10 cents $/{ }^{\circ} \mathrm{C}$ for BOEC in Table II.1-5 of the ABTR design report [7].

Table 12: Doppler coefficient of reactivity [cents $/ K](\beta=0.0033)$.

\begin{tabular}{c|c|c|c}
$\begin{array}{c}\text { Fuel temp. range } \\
{[K]}\end{array}$ & Serpent & Griffin & \% rel. diff. \\
\hline $600-805$ & -0.13 & -0.13 & 0.00 \\
$805-855$ & -0.10 & -0.10 & -0.01 \\
$855-905$ & -0.19 & -0.19 & 0.01 \\
$905-955$ & -0.08 & -0.08 & -0.71 \\
$955-1155$ & -0.09 & -0.09 & 0.16
\end{tabular}

The radial expansion coefficients of reactivity computed with Griffin are included in Table 13 . The predicted values are consistent with the reported value of -0.59 cents $/{ }^{\circ} \mathrm{C}$ for BOEC in Table II.1-5 of the ABTR design report [7].

Table 13: Radial expansion coefficients of reactivity with the fuel temperature at $855 \mathrm{~K}$ and $\beta=0.0033$.

\begin{tabular}{c|c}
$\begin{array}{c}\text { Plate temp. range } \\
{[K]}\end{array}$ & $\begin{array}{c}\frac{\Delta \rho}{\Delta T} \\
{[\text { cents } / K]^{2}}\end{array}$ \\
\hline $295-600$ & -0.54 \\
$600-805$ & -0.60 \\
$805-855$ & -0.64
\end{tabular}




\subsubsection{Model Based on Nonuniform Temperature Distributions}

A comparison of the fundamental mode eigenvalues for each state point between the reference Serpent and Griffin calculations is shown in Table 14. In all cases, Griffin reproduces the eigenvalue within the statistical uncertainty of the Monte Carlo reference. We confirmed the accuracy of the solution by examining the fission rate in all SPH regions from Table 15 . The maximum relative difference in the fission rate in any $\mathrm{SPH}$ zone is $0.00672 \%$ of the reference Monte Carlo.

Table 14: Fundamental mode eigenvalues at each state point with a nonuniform temperature distribution.

\begin{tabular}{c|c|c|c|c|c} 
Case & $\begin{array}{c}\text { Temp } \\
{[K]}\end{array}$ & $\begin{array}{c}\text { Serpent } \\
k_{\text {eff }}\end{array}$ & $\begin{array}{c}\text { Serpent } \\
\text { uncert }\end{array}$ & $\begin{array}{c}\text { Griffin } \\
k_{\text {eff }}\end{array}$ & $\begin{array}{c}\text { Difference } \\
{[p c m]}\end{array}$ \\
\hline 1 & 600 & 1.03187 & $1.70 \mathrm{E}-05$ & 1.03187 & -0.08 \\
2 & 805 & 1.03080 & $1.60 \mathrm{E}-05$ & 1.03080 & -0.07 \\
3 & 855 & 1.03058 & $1.70 \mathrm{E}-05$ & 1.03058 & -0.07 \\
4 & 905 & 1.03029 & $1.60 \mathrm{E}-05$ & 1.03029 & -0.07 \\
5 & 955 & 1.03009 & $1.70 \mathrm{E}-05$ & 1.03009 & -0.07 \\
6 & 1155 & 1.02946 & $1.70 \mathrm{E}-05$ & 1.02946 & -0.07
\end{tabular}

Table 15: \% relative difference in the FoMs for the power distribution at each state point with a nonuniform temperature distribution.

\begin{tabular}{c|c|c|c|c} 
Case & $\begin{array}{c}\text { Temp } \\
{[K]}\end{array}$ & RMS & Max. & Min. \\
\hline 1 & 600 & $3.17 \mathrm{E}-03$ & $6.72 \mathrm{E}-03$ & $6.09 \mathrm{E}-07$ \\
2 & 805 & $2.68 \mathrm{E}-03$ & $5.97 \mathrm{E}-03$ & $6.68 \mathrm{E}-06$ \\
3 & 855 & $1.99 \mathrm{E}-03$ & $4.50 \mathrm{E}-03$ & $3.71 \mathrm{E}-06$ \\
4 & 905 & $2.90 \mathrm{E}-03$ & $6.26 \mathrm{E}-03$ & $8.08 \mathrm{E}-06$ \\
5 & 955 & $2.37 \mathrm{E}-03$ & $5.07 \mathrm{E}-03$ & $7.36 \mathrm{E}-06$ \\
6 & 1155 & $2.70 \mathrm{E}-03$ & $5.55 \mathrm{E}-03$ & $1.37 \mathrm{E}-06$
\end{tabular}

The Doppler coefficients of reactivity computed with Griffin for the nonuniform case are included in Table 16. The predicted values are consistent with the reported value of -0.10 cents $/{ }^{\circ} \mathrm{C}$ for BOEC in Table II.1-5 of the ABTR design report [7]. The values for the nonuniform case are generally higher than those for the uniform case. This might imply that this model experiences a larger Doppler feedback during the transient simulations. We verified the radial thermal expansion feedback from this model to be consistent with Table 13 . 
Table 16: Doppler coefficient of reactivity nonuniform temperature distribution[cents/K] $(\beta=0.0033)$.

\begin{tabular}{c|c|c|c}
$\begin{array}{c}\text { Fuel temp. range } \\
{[K]}\end{array}$ & Serpent & Griffin & \% rel. diff. \\
\hline $600-805$ & -0.15 & -0.15 & 0.01 \\
$805-855$ & -0.12 & -0.12 & 0.01 \\
$855-905$ & -0.16 & -0.16 & 0.00 \\
$905-955$ & -0.11 & -0.11 & 0.01 \\
$955-1155$ & -0.09 & -0.09 & 0.01
\end{tabular}

\subsubsection{Kinetic Parameters}

A comparison of the kinetics parameters obtained from the Serpent and Griffin models for both uniform and nonuniform temperature distributions are shown in Tables 17, 18, and 19. The Griffin values were obtained with the IQS method [12]. Differences in the mean generation time are not unexpected since the values tend to be dependent on the group structure, the use of SPH correction, and the convergence of the solution. We observe a $12 \%$ bias on the mean generation time. There is also $-12 \%$ bias on the beta values between the Serpent and Griffin models. Currently, Serpent generates a $\beta_{\text {eff }}$ for each cross-section region using the Meulekamp method [13]. INL is currently investigating these issues with the kinetic parameters.

Table 17: Neutron mean generation.

\begin{tabular}{c|c} 
Model & $\Lambda$ \\
\hline Serpent uniform & $4.04 \mathrm{E}-07$ \\
Serpent nonuniform & $4.05 \mathrm{E}-07$ \\
Griffin uniform & $4.52 \mathrm{E}-07$ \\
Griffin nonuniform & $4.53 \mathrm{E}-07$
\end{tabular}

Table 18: Neutron fractions $(\beta)$ for the delayed neutron precursors.

\begin{tabular}{c|cccccc} 
Model & 1 & 2 & 3 & 4 & 5 & 6 \\
\hline Serpent uniform & $8.185 \mathrm{E}-05$ & $5.941 \mathrm{E}-04$ & $5.067 \mathrm{E}-04$ & $1.191 \mathrm{E}-03$ & $7.032 \mathrm{E}-04$ & $2.574 \mathrm{E}-04$ \\
Serpent nonuniform & $8.206 \mathrm{E}-05$ & $5.923 \mathrm{E}-04$ & $5.068 \mathrm{E}-04$ & $1.195 \mathrm{E}-03$ & $7.024 \mathrm{E}-04$ & $2.574 \mathrm{E}-04$ \\
Griffin uniform & $7.179 \mathrm{E}-05$ & $5.217 \mathrm{E}-04$ & $4.469 \mathrm{E}-04$ & $1.051 \mathrm{E}-03$ & $6.203 \mathrm{E}-04$ & $2.275 \mathrm{E}-04$ \\
Griffin nonuniform & $7.191 \mathrm{E}-05$ & $5.212 \mathrm{E}-04$ & $4.471 \mathrm{E}-04$ & $1.052 \mathrm{E}-03$ & $6.205 \mathrm{E}-04$ & $2.273 \mathrm{E}-04$
\end{tabular}


Table 19: Decay constants $(\lambda)$ for the delayed neutron precursors.

\begin{tabular}{c|cccccc} 
Model & 1 & 2 & 3 & 4 & 5 & 6 \\
\hline Serpent uniform & $1.338 \mathrm{E}-02$ & $3.100 \mathrm{E}-02$ & $1.176 \mathrm{E}-01$ & $3.094 \mathrm{E}-01$ & $8.855 \mathrm{E}-01$ & $2.945 \mathrm{E}+00$ \\
Serpent nonuniform & $1.338 \mathrm{E}-02$ & $3.100 \mathrm{E}-02$ & $1.176 \mathrm{E}-01$ & $3.093 \mathrm{E}-01$ & $8.855 \mathrm{E}-01$ & $2.945 \mathrm{E}+00$ \\
Griffin uniform & $1.338 \mathrm{E}-02$ & $3.100 \mathrm{E}-02$ & $1.177 \mathrm{E}-01$ & $3.094 \mathrm{E}-01$ & $8.857 \mathrm{E}-01$ & $2.946 \mathrm{E}+00$ \\
Griffin nonuniform & $1.338 \mathrm{E}-02$ & $3.100 \mathrm{E}-02$ & $1.177 \mathrm{E}-01$ & $3.094 \mathrm{E}-01$ & $8.857 \mathrm{E}-01$ & $2.946 \mathrm{E}+00$
\end{tabular}

\subsection{Steady State}

When simulating the steady state condition, all the simulations resulted in nearly the same solutions. This indicates the solution was not really sensitive to the thermal expansion effects or the temperature distribution that was used to generate the SPH factors.

A coupled steady-state solution was generated to ensure that accurate initial conditions were input into the transient. This is important for multiple reasons, but the main reason is the neutronics calculations. Any slight deviation from true initial conditions could introduce a large amount of positive or negative excess reactivity. This could result in a wrong solution or an unstable solution. In order to make sure this reactivity addition did not occur, the coupled physics needed to be solved in conjunction with the neutronics so that the coupled effects did not introduce reactivity due to poor initial conditions to the transient. To check this, a null transient was run to ensure that the transient solver can maintain that steady-state solution without instability.

Table 20: Steady-state eigenvalues for each simulation with uniform and nonuniform corrections.

\begin{tabular}{c|cc} 
Coupling & Uniform eigenvalue & Nonuniform eigenvalue \\
\hline Griffin and SAM & 1.030903 & 1.030940 \\
Griffin, SAM, and grid plate expansion & 1.024351 & 1.024388 \\
Griffin, SAM, and grid plate and fuel expansion & 1.022039 & 1.022075
\end{tabular}

\subsection{Unprotected Loss of Flow Transient}

A ULOF accident is considered a beyond-design-basis accident (BDBA) for the ABTR system. The sequence assumes that power is lost permanently to the primary and secondary coolant pumps and assumes that reactivity scram mechanisms fail. This essentially forces the reactor to adjust power through feedback mechanisms to a safe level without system failure. This is the accident that we will simulate. To do this, the only accident specific inputs that are needed for the 
simulation are the pump coast down curves that describe the head generating capability of the pumps with respect to time.

We ran three sets of simulations to investigate the cumulative effects of each feedback mechanism. The first simulation was simply a Griffin and SAM coupling that demonstrated the cores temperature response during the ULOF transient. The thermomechanic multi-app was simply removed from the simulation altogether. The second simulation included what was considered the largest component of the feedback behavior, as determined by previous work [7, 10]. This was the core radial expansion caused by the grid plate and core superstructure expanding from the increased pool temperatures. The last simulation included the axial expansion of the fuel on an assembly by assembly basis. This was another minor contributor to the feedback behavior of the system, but, as the results show, these feedback mechanisms can have large effects on the behavior of the system as a whole.

\subsubsection{No Thermal Expansion}

The runs that did not include thermal expansion were a simple coupling of Griffin to SAM. This allowed us to simulate the transient temperature behavior. This transient is expected to progress more slowly than the others because a major portion of the reactivity feedback within the core is due to the thermal expansion effects.

\subsubsection{Grid Plate Expansion}

When including the grid plate thermal expansion, the core differences between the crosssection sets shrink. The results also look more like a prior analysis from [7, 10]. This is because the grid plate thermal deformation is the dominant reactivity feedback mechanism and will allow a more rapid temperature response of the core.

In all the runs, there is a rise in temperature at around 600 seconds. This rise in temperature is simply a result of the mass flowrate and the reactor power. Looking at Equation 2, the relationship between flow, power, and temperature difference can be seen in a simplified manner. If the time dependent values for power and mass flow are taken from the simulation and $C_{p} \Delta T$ is isolated, then the shape obtained is consistent with the shape of the results. This relationship can be seen in Figure 14 for the ulof transient. The same behavior also applies in the axial expansion case but the 
same plot will not be shown. This phenomena occurs because the flow momentum is dominated by the recently shutdown pump and the necessary gradient has not yet been established through natural circulation to drive the flow. The temperature then begins to rise to establish that gradient. At 1,000 seconds, we consider the transient over, but we expect that, if enough time is given, both the power and core outlet temperature will achieve asymptotic behavior.

$$
Q=\dot{m} C_{p} \Delta T
$$

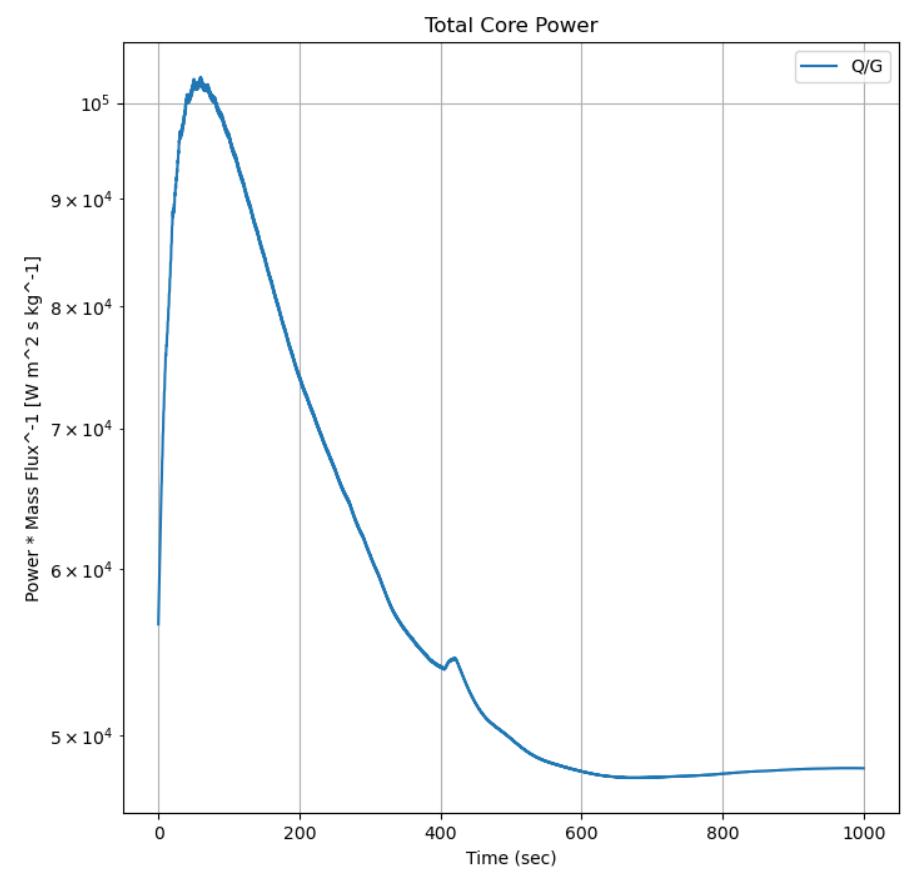

Figure 14: The power quantity over the mass flux for the transient.

\subsubsection{Fuel Axial and Grid Plate Expansion}

The last set of simulations we performed included axial expansion. All the major reactivity effects are in the model, and this model gives an idea of what the real world response would be for the ULOF transient. Because the radial expansion dominates the reactivity, this transient is expected to show similar behavior to the prior simulations. 


\subsubsection{Analysis}

Three significant variables are analyzed because they are important quantities that show the various effects in the transient. The hot pool temperature is the plenum immediately outside of the core exit where all the core channels mix. This is what all the heat exchangers draw from on their hot side inlet. The inner core outlet temperature is the fluid temperature at the outlet of the inner region of the core. Then finally the power, which is going to be driving the transient and temperature behavior in the core, is reported for each of the cases.

When the ULOF transient begins, the hot pool temperature begins to increase in all cases as the heat exchangers stop removing heat from the system. The reactor is at full power initially, so the temperature rise is dramatic. As the temperature increases, the neutronic feedback causes the power to decrease. This decrease is where the cases diverge, as can be seen in Figure 15.

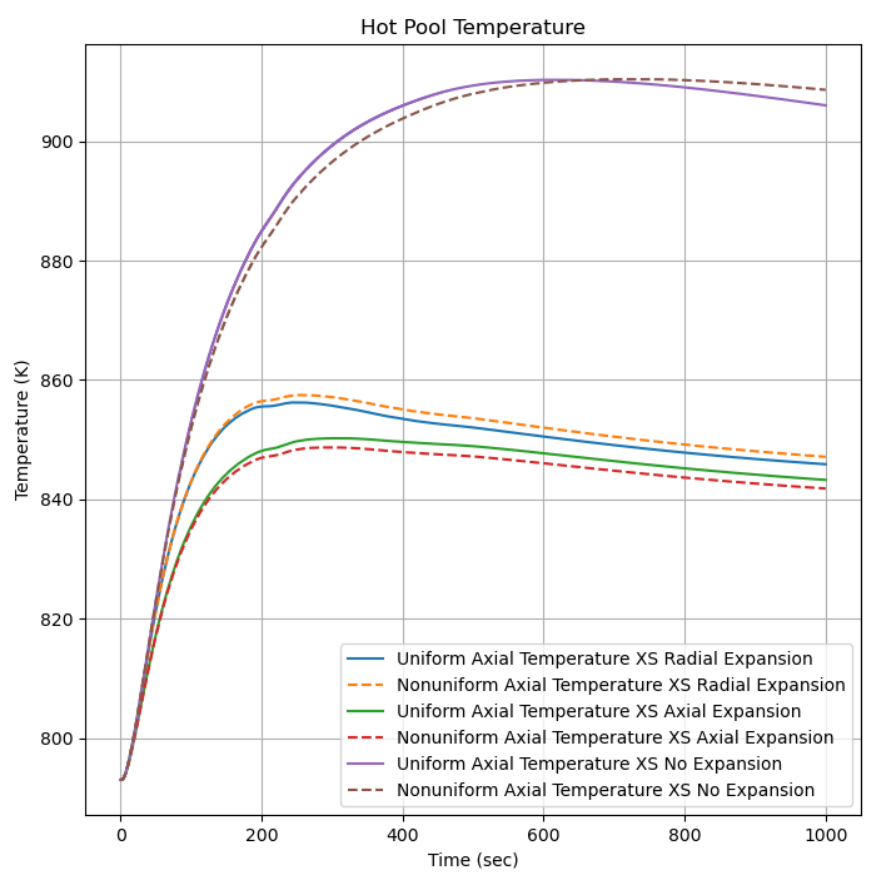

Figure 15: Hot pool temperature for the various cases as a function of time.

In the legends of all the following plots XS means cross-section. As was expected, the case that relied solely on temperature effects resulted in the highest temperatures because temperature alone is not a dominant reactivity mechanism. Higher temperatures reduced the power. When 
radial expansion is added the peak temperature is reduced and axial expansion adds a slight additional change when included.

The uniform temperature profile SPH correction factors and the nonuniform profiles were run. These are the dashed lines in the plots. The difference between the results using each set of correction factors and the reasons for why these differences present need to be examined. Figure 16 shows the relative difference between the two solutions as a function of time.

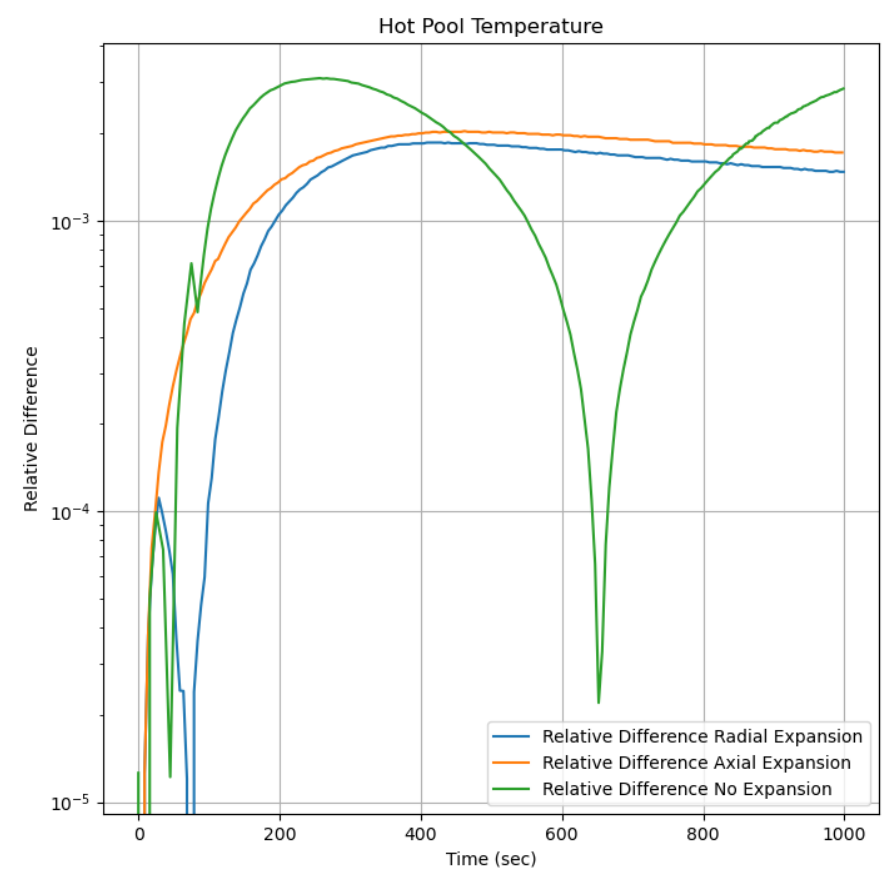

Figure 16: The relative difference between the uniform and nonuniform SPH corrections on the hot pool temperature.

The inner core temperature shows similar behavior to the hot pool except the temperature changes are more extreme. As discussed earlier, the temperature for the radial and axial expansion runs increases later in the transient. This is simply the relationship between the mass flow and power for the transient. Figure 17 shows the outlet temperature of the inner region as a function of time for each simulation.

The results are similar to the prior work in that the general shape was as we expected and that the results tend to agree with prior work done. It agrees well with [10] for the shape of the outlet temperature transient, even including a similar hump at around 400 seconds when the pump 


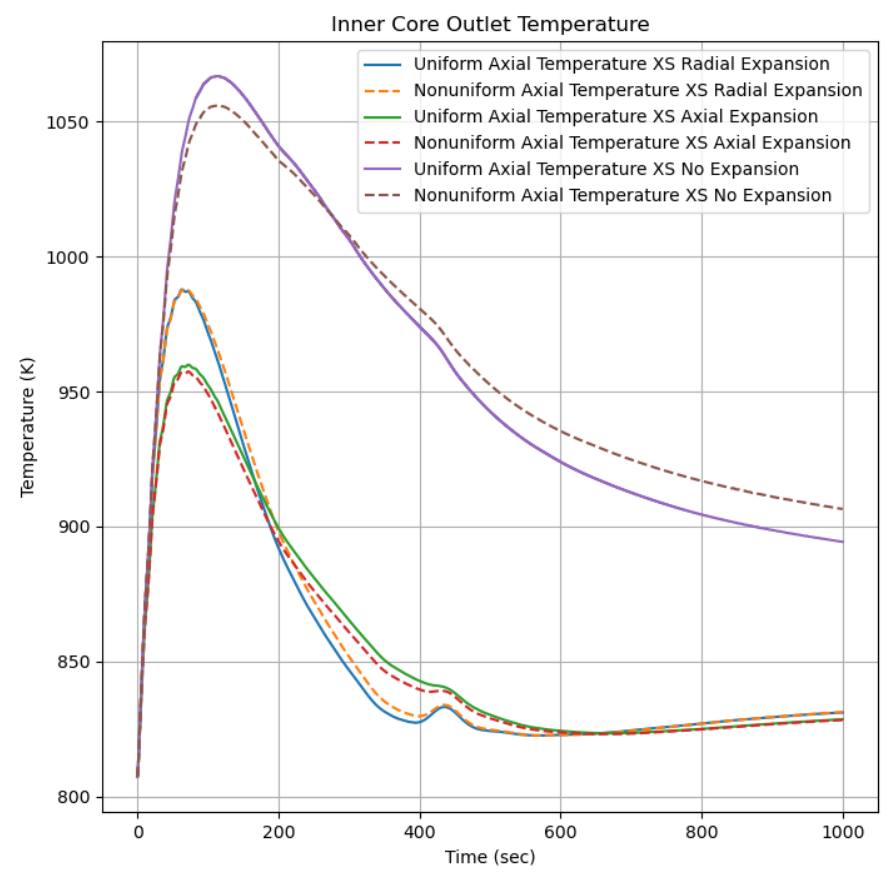

Figure 17: Temperature of the outlet of the inner core region versus time.

finally ramps to 0 when including axial and radial expansion.

When comparing the different SPH factors, it is possible to determine that the more complex models perform better with respect to differences. The results between uniform and nonuniform results only have a small period where there is a significant difference. The model without thermal expansion has a much larger discrepancy though. This can be seen in Figure 18.

The power is less dynamic in its behavior but is important to consider. As we expected, the power transient progressed more quickly as more reactivity mechanisms were included. This can be seen in Figure 19

This is a plot with a logarithmic y axis to highlight the difference between the no axial expansion runs and some interesting effects related to the expansion. At the end of the 1,000 second transient, the power of the no thermal expansion runs was about five times higher than when thermal expansion was included. This is why the temperatures were much higher and this was expected because the thermomechanical effects are the dominant reactivity mechanisms. The radial thermal expansion add a substantial portion of the temperature effects relating to feed back. 


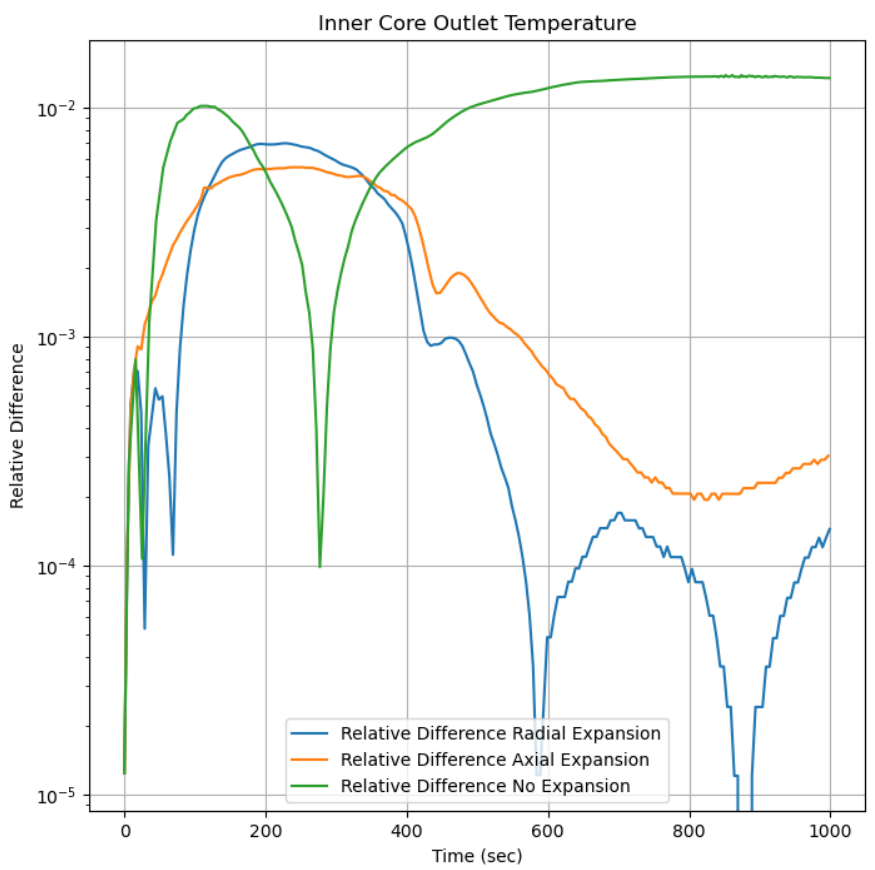

Figure 18: Relative difference between the outlet temperature for each transient.

When including axial thermal expansion, the final power and the transient power is almost the same as with radial expansion alone.

When axial expansion is included, it actually reduces the speed at which power is reduced overall. Initially, the power decreases much faster, causing less energy to accumulate in the system. With less energy comes lower temperatures, and those lower temperatures cause the power decrease to slow down later in the transient.

The power results in the largest relative differences between the uniform and nonuniform profiles. The relative differences between the results can be seen in Figure 20.

In all of these cases, the difference between the solutions is caused by the changing axial temperature profile of the fuel. At steady state, the temperature profile is determined from the fluid temperature and the power production within the fuel. At the end of the transient, the temperature of the fuel is dominated by the fluid temperature surrounding it. This changes the shape and, as a result, reduces the accuracy of the SPH correction over time. 


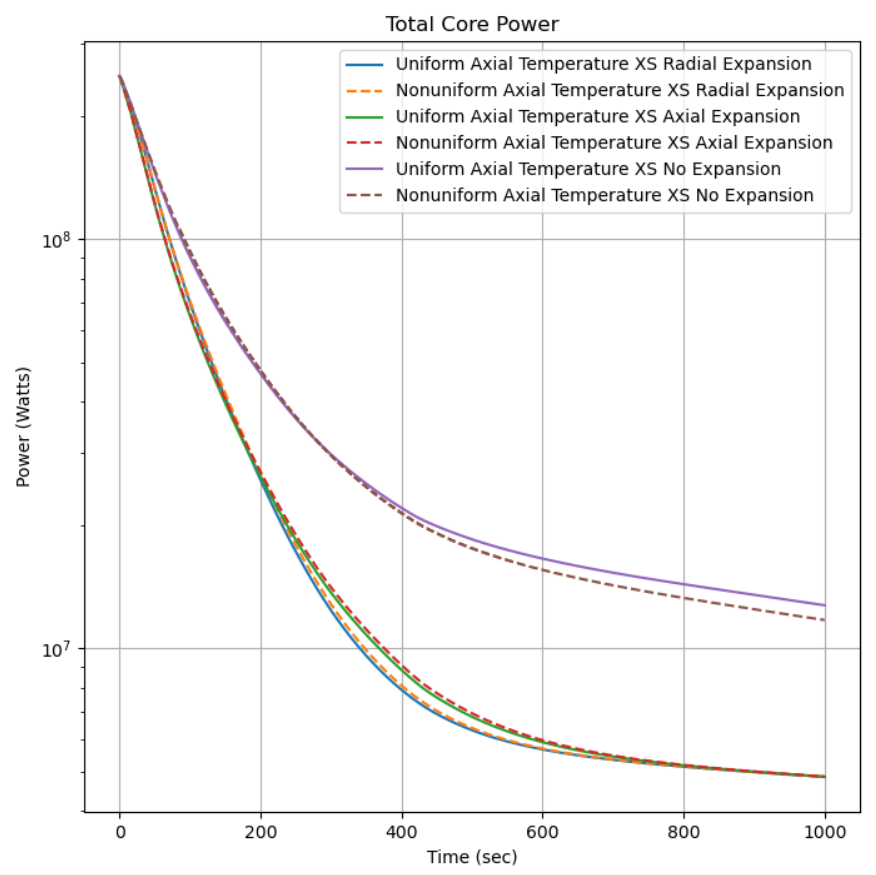

Figure 19: Reactor power versus time throughout the ULOF transient.

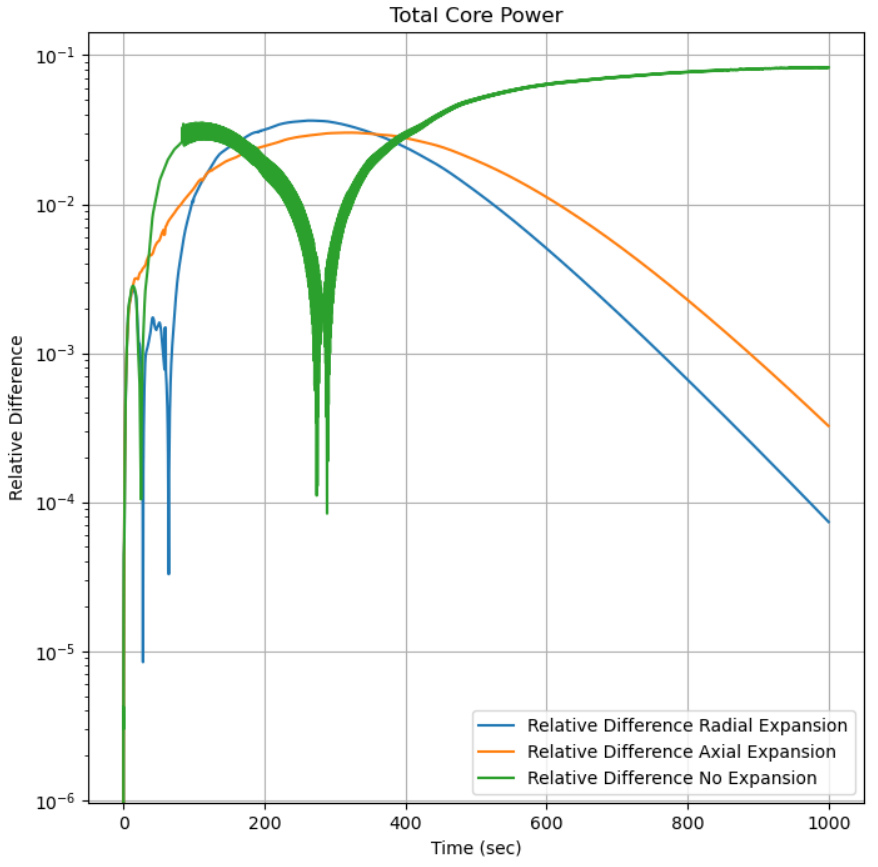

Figure 20: Relative difference between the power for each transient. 


\section{CONCLUSIONS AND FUTURE WORK}

This report details the progress and activities of INL for the NRC project "Development and Modeling Support for Advanced Non-Light Water Reactors," for which we report the successful completion of Task $4 \mathrm{~b}$.

A 3D Griffin model of the ABTR has been coupled to SAM to perform the ULOFtransient. The model includes various explicit feedback mechanisms for fast reactors, including Doppler, radial expansion from the displacement of the support plate, and axial expansion from the displacement of the fuel pins.

The transient shows that the models can give realistic results. As the analysis complexity increased, the changes in the results were in line with what we expected, based on previous analysis and engineering intuition. The dominant reactivity mechanism was radial expansion. When looking at temperature effects alone, the results are as expected, with a much slower response from the system. With axial expansion, the response of the system is slightly increased. The differences between the SPH correction factors diminished as more dominant reactivity mechanisms were added. Additional model complexity should be pursued in future work.

The current thermal expansion feedback model assumes that all homogenized materials are displaced jointly, uniform re-homogenization, whereas in reality this is not the case. The density changes are material dependent, and the sodium fills or extrudes from volumes as the displacements occur. To improve the thermal expansion feedback model in Griffin, one must consider the density changes of the various materials and re-homogenize the cross sections based on the individual volumes. Future work can focus on the re-homogenization of cross sections based on specific material density changes to assess the impact of the uniform homogenization assumption.

To obtain a higher fidelity model it is desired to add the differential expansion experienced from the control rod positioning and fuel thermal expansion. The control rods are axially sitting in a variable temperature fluid and generating internal power themselves, so both the positioning of the control rods and density of the control rod material will be time dependent. Given the average temperature of the core and the ABTR pool increases over the transient, the control rods should expand further into the core giving an additional margin in the accident. In addition, two further improvements should also be considered: 1) the sodium density feedback and 2) the 
enhancement of the kinetics parameters.

Currently, the model only includes four subchannels, which represent the entire core. This is not because of code limitations but because of performance limitations. Including individual channels in SAM results in poor convergence in the linear iterations of the solver, which results in long computational times. It is also not recommended to run SAM on multiple processes, as the decomposition of the mesh introduces lagged behavior and instability in the solver. It can be run in parallel with multiple threads, but testing showed that, currently, the gain in performance was not significant enough to make this realistic. Inputs were generated that allow for 60 subchannels, one per assembly, to be solved but were not run in transient, as the steady-state solutions took a prohibitive amount of time to solve.

Finally, future work should include a more accurate support plate mesh and the addition of constraints on the expansion of the core structural components to improve the dimensional changes that have a large effect on the transient, as was demonstrated in the results. The support plate and the fuel are not free floating objects and have some resistance to movement as a result of their positioning in the core super structure. 


\section{REFERENCES}

[1] C. J. Permann, D. R. Gaston, D. Andrš, R. W. Carlsen, F. Kong, A. D. Lindsay, J. M. Miller, J. W. Peterson, A. E. Slaughter, R. H. Stogner, and R. C. Martineau, “Moose: Enabling massively parallel multiphysics simulation," SoftwareX, vol. 11, p. 100430, 2020.

[2] T. K. Kim, "Benchmark Specification of Advanced Burner Test Reactor," Tech. Rep. ANL/NSE-20/65, Argonne National Laboratory, 122020.

[3] J. Leppänen,, Development of a New Monte Carlo Reactor Physics Code. PhD thesis, Helsinki University of Technology, 2007.

[4] J. Ortensi, Y. Wang, A. Laurier, S. Schunert, A. Hébert, and M. DeHart, "A Newton solution for the Superhomogenization method: The PJFNK-SPH," Annals of Nuclear Energy, vol. 111, pp. 579-594, 12018.

[5] N. Messaoudi and J. Tommasi, "Fast burner reactor devoted to minor actinide incineration," Nuclear Technology, vol. 137:2, pp. 84-96, 2002.

[6] W. S. Yang, T. K. Kim, S. J. Kim, and C. H. Lee, "Preliminary validation studies of existing neutronics analysis tools for advanced burner reactor design applications," Tech. Rep. ANLAFCI-186, Argonne National Laboratory, 2007.

[7] J. Cahalan, L. Deitrich, F. Dunn, D. Fallin, M. Farmer, T. Fanning, T. Kim, L. Krajtl, S. Lomperski, A. Moisseytsev, Y. Momozaki, J. Sienicki, Y. Park, Y. Tang, C. Reed, C. Tzanos, S. Wiedmeyer, W. Yang, and Y. Chikazawa, “Advanced Burner Test Reactor Preconceptual Design Report," Tech. Rep. ANL-ABR-1, Argonne National Laboratory, 92006.

[8] “Decay Heat Power in Light Water Reactors," Tech. Rep. ANSI/ANS-5.1-2014, American Nuclear Society, 22019.

[9] R. Hu, "Sam theory manual," tech. rep., Argonne National Lab.(ANL), Argonne, IL (United States), 2017.

[10] G. Hu, G. Zhang, and R. Hu, "Reactivity Feedback Modeling in SAM," Tech. Rep. ANL-NSE19, Argonne National Laboratory, 42019. 
[11] R. Morris, “Cubit 15.0 user documentation," tech. rep., ETI, UT, 2014.

[12] Z. M. Prince, J. C. Ragusa, and Y. Wang, "Implementation of the Improved Quasi-static Method in RATTLESNAKE/MOOSE for Time-dependent Radiation Transport Modelling," in PHYSOR 2016: Unifying Theory and Experiments in the 21st Century, (Sun Valley, ID), American Nuclear Society, May 1-5 2016.

[13] R. K. Meulekamp and S. C. van der Marck, "Calculating the effective delayed neutron fraction with monte carlo," Nuclear Science and Engineering, vol. 152, no. 2, pp. 142-148, 2006. 